\title{
1 Disaggregation of SMOS Soil Moisture over the Canadian Prairies
}

\author{
Najib Djamai ${ }^{1}$, Ramata Magagi ${ }^{1}$, Kalifa Goita ${ }^{1}$, Olivier Merlin ${ }^{2}$, Yann Kerr ${ }^{2}$, Anne \\ Walker $^{3}$
}

$8{ }^{1}$ CARTEL, Département de géomatique appliquée, Université de Sherbrooke (Canada)

$9{ }^{2}$ Centre d'Études Spatiales de la Biosphère (France)

$10{ }^{3}$ Environment Canada (Canada)

Abstract- In this study, we used the Disaggregation based on Physical And Theoretical

15 scale Change (DISPATCH) algorithm under very wet soil conditions in Western Canada

16 for the disaggregation of coarse resolution $40-\mathrm{km}$ soil moisture derived from the Soil

17 Moisture Ocean Salinity (SMOS) satellite. The algorithm relies on the Soil Evaporative

18 Efficiency (SEE), which was estimated using the $1-\mathrm{km}$ resolution data from the

19 MODerate resolution Imaging Spectoradiometer (MODIS). The study aimed to: (i)

20 evaluate DISPATCH under wet soil conditions, (ii) test the linearity/non-linearity of the

21 relationship between soil moisture and SEE, and (iii) propose a more robust procedure to

22 calibrate the SEE model under very wet soil conditions. The disaggregated soil moisture

23 values were compared to $0-5 \mathrm{~cm}$ in situ measurements and the soil moisture derived from

24 the L-MEB (L-band Microwave Emission of the Biosphere) model from airborne

25 brightness temperature at $1.4 \mathrm{GHz}$ collected during the Canadian Experiment for Soil

26 Moisture in 2010 (CanEx-SM10) field campaign. The results show a correlation between

270.7 and 0.8 and bias values $\sim 0 \mathrm{~m}^{3} / \mathrm{m}^{3}$. The DISPATCH algorithm shows better

28 disaggregation results under very wet soil conditions when a non-linear relationship is 
29 considered between SEE and soil moisture instead of a linear model. This is mainly due

30 to the small variability of surface temperature inside the area covered by the SMOS pixel

31 under very wet soil conditions, and the difficulty in accurately estimating the maximum

32 soil temperature $\left(T s_{\max }\right)$, which is a driving factor for SEE. A sensitivity analysis was

33 conducted and it shows that the linear model performs well only if $T s_{\max }$ can be

34 determined more accurately. The possibility to determine $T s_{\max }$ using high resolution

35 MODIS data over a larger area than the SMOS pixel is examined and discussed in the

36 paper.

37 Keywords: Soil moisture, SMOS, disaggregation, DISPATCH algorithm, Canex-SM10, 38 Canada.

\section{Introduction}

43 al., 2014), meteorology (Loew et al., 2013) and agriculture (Narasimhan et al., 2005).

44 This parameter is highly variable both spatially and temporally, as the result of the 45 heterogeneity of soil properties, topography, land cover, rainfall, and evapotranspiration.

46 Remote sensing data can provide frequent and spatially estimates of surface soil moisture 47 (Kerr et al., 2010; Njoku et al., 2003; Wagner et al., 2013). Results from many 48 experimental studies suggest that the L-band in passive mode is optimal for estimating

49 surface soil moisture, due to its greater emitting depth, its lower sensitivity to surface

50 roughness and vegetation effects, and its independence of weather conditions (Njoku et

51 al., 1996; Kerr et al., 2007). The Soil Moisture and Ocean Salinity (SMOS) satellite of

52 the European Space Agency (ESA), in orbit since 2 November 2009, is the first L-band 53 passive microwave satellite. One of its objectives is to map surface soil moisture at global 
54 scale with accuracy better than $0.04 \mathrm{~m}^{3} / \mathrm{m}^{3}$ (Kerr et al., 2010). With its innovative

55 technology based on a two-dimensional interferometric radiometer, SMOS is able to

56 estimate soil moisture at a depth of up to $5 \mathrm{~cm}$, with a repeat cycle of less than 3 days and

57 a spatial resolution of about $40 \mathrm{~km}$. This coarse spatial resolution is adequate for

58 applications at global scale, but it is low for studies at regional and local scales that

59 require data with a resolution of 1 to $10 \mathrm{~km}$ (Entekhabi et al., 2010). Spaceborne passive

60 microwave sensors are characterized by their very low spatial resolution in general. The

61 Advanced Microwave Scanning Radiometer - Earth Observing System (AMSR-E), has a

62 resolution of about $60 \mathrm{~km}$ resolution, it is less sensitive to soil moisture than the L-band

63 ( $\mathrm{X}$ and $\mathrm{C}$ bands are the lowest frequencies used for soil moisture retrievals). As for the

64 Soil Moisture Active and Passive (SMAP) mission, the spatial resolutions of the passive

65 and active microwave sensors are about $40 \mathrm{~km}$ and $3 \mathrm{~km}$, respectively (Entekhabi et al.,

66 2010). To address the problem of scale mismatch between its large-scale passive

67 microwave estimates and local scale applications, SMAP will also provide soil moisture

68 products at $9 \mathrm{~km}$ resolution by combining L-band passive and active microwave

69 measurements (Das et al., 2011). Alternative downscaling approaches are based on

70 optical/thermal remotely sensed data (Chauhan et al., 2003; Merlin et al., 2008; Piles et

71 al., 2011).

72 Optical/thermal satellite sensors provide data at fine spatial resolution and shorter revisit

73 time (1 day) compared to Synthetic Aperture Radar sensors ( $\sim 15$ days). However, despite

74 some potential to monitor soil moisture (Idso et al., 1975; Weidong et al., 2003), their

75 sensitivity to other environmental factors, particularly vegetation cover and weather

76 conditions, makes retrieving soil moisture impractical (Wang et al., 2007) from 
77 optical/thermal data alone. However, their synergistic use with passive microwave

78 measurements, which are highly sensitive to soil moisture, appears as a promising

79 approach to retrieve soil moisture at finer scales. Indeed, based on the "universal

80 triangle" concept, Carlson et al. (1994) showed an empirical polynomial relationship

81 between soil moisture, soil temperature and vegetation cover. Since then, efforts are

82 being made to downscale passive microwave soil moisture estimates using

83 optical/thermal data (Chauhan et al., 2003; Merlin et al., 2008; Piles et al., 2011).

84 However, the downscaling methodologies still need to be validated for a range of hydro-

85 climatic conditions, and subsequently improved. Chauhan et al. (2003) used the universal

86 triangle concept to infer high-resolution soil moisture from coarse resolution soil

87 moisture derived from the Special Sensor Microwave Imager (SSM/I) data and optical

88 data from the Advanced Very High Resolution Radiometer (AVHRR). Later, Merlin et

89 al. (2008) improved this approach by using a semi-empirical model to express the

90 relationship between the Soil Evaporative Efficiency (SEE) and near-surface soil

91 moisture. Linear and non-linear models have been proposed to link the evaporative

92 efficiency to soil moisture. However, the performance of each type of model in the

93 disaggregation literature has not yet been extensively discussed. Other, slightly different,

94 disaggregation methods are proposed in the literature. Piles et al., (2011) and Sánchez-

95 Ruiz et al., (2014) suggested the combination of coarse resolution SMOS brightness

96 temperature with the MODIS land surface temperature and Normalized Difference

97 Vegetation Index to disaggregate SMOS soil moisture estimates at MODIS scale. A

98 correlation coefficient of up to 0.72 was found between their results and the ground truth

99 data. Rahimzadeh-Bajgiran et al. (2013) replaced the surface temperature axis in the 
100 "universal triangle" space by the difference between the surface temperature and air 101 temperature derived from the North American Regional Reanalysis (NAAR). In addition,

102 to show improvements due to the integration of air temperature into the surface

103 temperature/vegetation index space, these authors found that downscaling methods based

104 on optical/thermal data led to better results for intermediate soil moisture conditions

105 (from 0.12 to $0.22 \mathrm{~m}^{3} / \mathrm{m}^{3}$ ) than for extreme soil moisture conditions. For these cases,

106 further studies are needed. Kim and Hogue (2012) considered various key factors

107 providing information on relative variations in surface wetness conditions. These factors

108 (i.e., surface temperature, vegetation indexes, and albedo) are derived from MODIS data

109 and used as weighting parameters for downscaling the low resolution AMSR-E soil

110 moisture. Comparing their results with those obtained from the method of Merlin et al.

111 (2008), authors noted that both techniques significantly improve the limited spatial

112 variability of the AMSR-E product.

113 DISPATCH (DISaggregation based on Physical And Theoretical scale CHange)

114 developed by Merlin et al. (2012a) is an improved version of the algorithm by Merlin et

115 al., (2008). DISPATCH uses a trapezoidal model instead of the "universal triangle" to

116 account for the effect of vegetation water stress at high resolution (Moran et al. 1994) in

117 the derivation of SEE from optical/thermal data. DISPATCH has shown good 118 performance over semi-arid sites located in Australia (Merlin et al., 2012b) and in Spain

119 (Merlin et al., 2013), especially if the linear model is used to express the relationship

120 between SEE and near-surface soil moisture. However, the SEE model considered

121 depends on "temperature end-members" which define the limits of the 122 "universal trapezoid", meaning soil maximum and minimum temperatures 
$123\left(T s_{\max }, T s_{\min }\right)$ and vegetation maximum and minimum temperatures $\left(T v_{\max }, T v_{\min }\right)$.

124 The accuracy of these parameters depends on several factors such as the land cover, the

125 meteorological conditions and the spatial variability of moisture in the study area. Thus,

126 further studies are needed to evaluate the applicability of the DISPATCH algorithm to a

127 wide range of surface conditions.

128 The objective of this research was to 1) evaluate the applicability of the DISPATCH

129 algorithm to wet soil conditions; 2 ) analyze the impacts of the linearity of the relationship

130 considered between SEE and the near surface soil moisture; and 3) propose a more robust

131 procedure to use the relationship between SEE and near soil moisture under wet soil

132 conditions for improved disaggregation results. The area considered experienced very

133 wet soil conditions (above $0.15 \mathrm{~m}^{3} / \mathrm{m}^{3}$ ) during the period of this study.

\section{2. Study area}

135

136 The study area corresponds to the agricultural site considered in the framework of the 137 SMOS validation effort in Canada. As shown in Figure 1.a, it is located in the Canadian

138 Prairies, near Kenaston (Province of Saskatchewan, Canada), within latitudes 51.14 to

$13951.70 \mathrm{~N}$, and longitudes 105.67 to $106.79 \mathrm{~W}$. A major field campaign, named CanEx-

140 SM10, was organized at the site from 1 to 15 June 2010 for the validation of SMOS data.

141 Detailed information on the field protocols and the collected data (both airborne and 142 ground-based) are available in Magagi et al., (2013), and in the dedicated website at the

143 University of Sherbrooke in Canada (http://pages.usherbrooke.ca/canexsm10/).

144 Figure 1.b shows the topography of the site along with soil moisture measurement 145 locations and the SMOS grid centers included in the study site and used in this paper. 


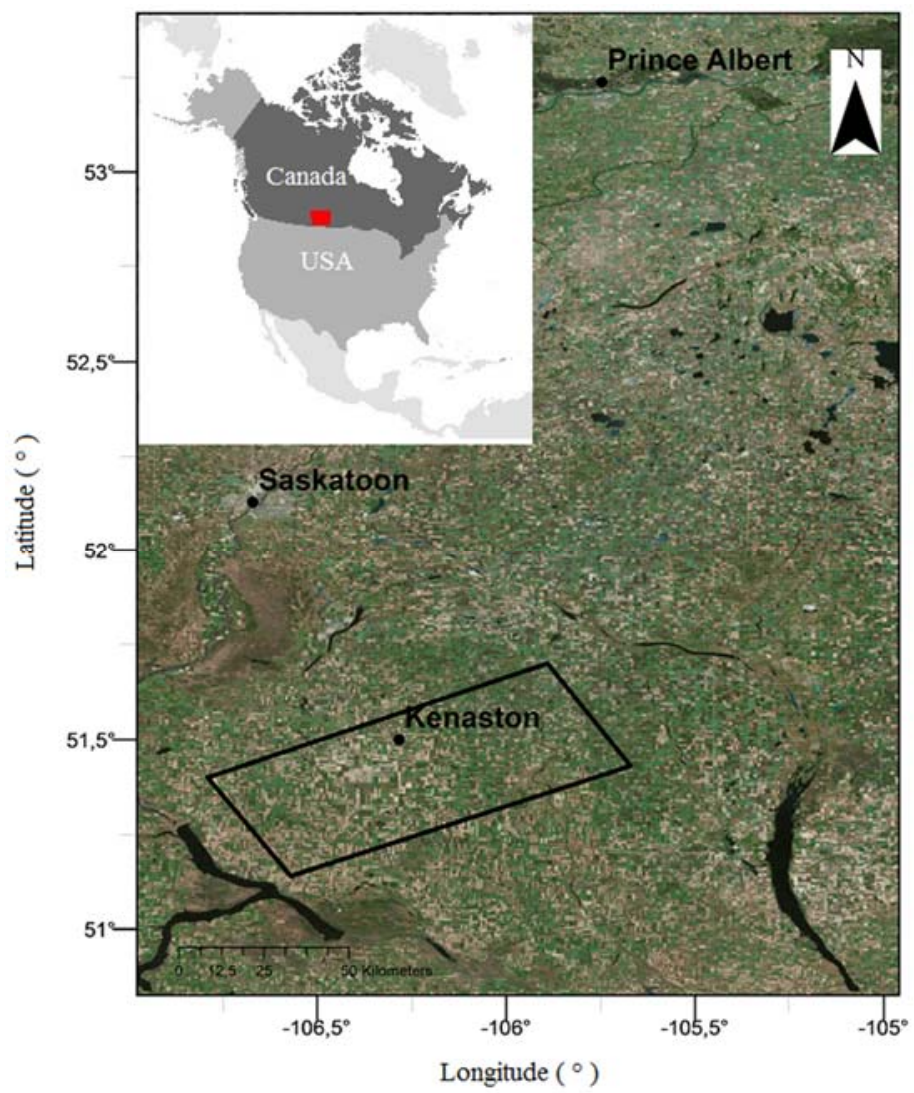

Figure 1.a: Study site

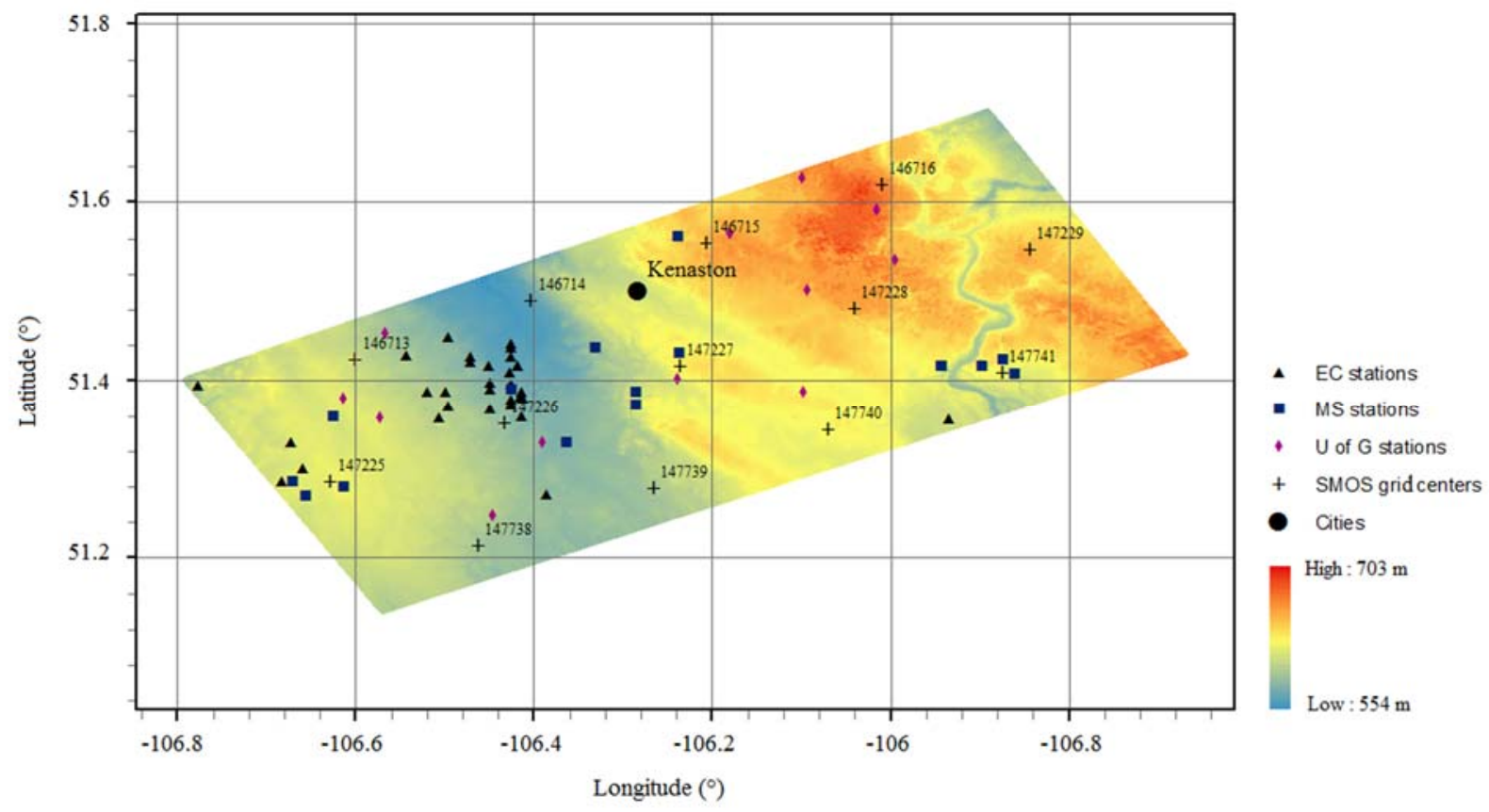

Figure 1.b: Digital Elevation Model, the ground-based measurements networks and 150 SMOS grid pixels for the Kenaston site. 


\section{3. Data description}

\section{$153 \quad$ 3.1.Ground measurements}

154 The ground measurements of soil moisture were conducted between 6 a.m. and mid-day 155 over 60 fields. Each field was about 800 x 800 m. Using Steven's Water Hydra Probe 156 sensors, the measurements were taken in each field, at a depth of $0-5 \mathrm{~cm}$, every $100 \mathrm{~m}$ at

15714 points distributed along two parallel transects $400 \mathrm{~m}$ apart. To ensure the 158 representativeness of the field data, at each point, three measurements of soil moisture 159 were taken (see the detailed protocol on the dedicated website). These field 160 measurements were calibrated using gravimetric soil moisture samples collected for each

161 field and on each sampling day. For comparison with the disaggregation results at a 162 resolution of $1 \mathrm{~km}$, the average soil moisture was calculated for each field. In addition to 163 soil moisture, other variables measured during the campaign were used in this study. This 164 includes surface roughness and soil texture information (sand and clay fractions).

165 Figure 2 shows the daily cumulative rainfall profile as well as the mean and the standard 166 deviation values of the soil moisture measurements for the 60 agricultural fields during 167 the field campaign period. The high amount of soil moisture results from the abundant 168 rainfall during and prior to the field campaign. As a consequence, agricultural practices 169 were delayed; the fields were almost bare and very wet (Magagi et al., 2013). 


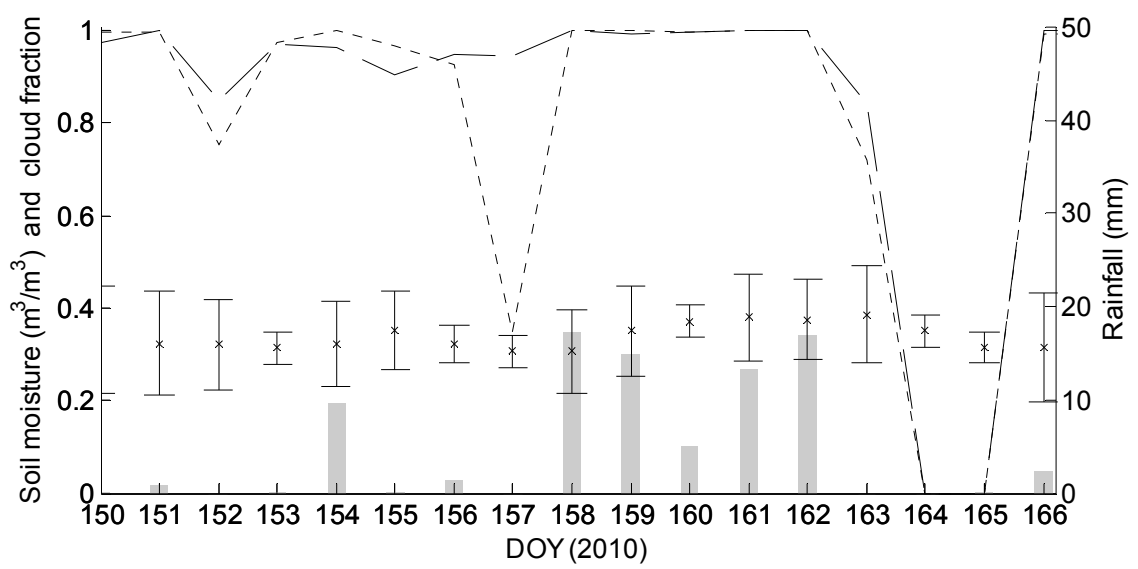

171 Figure 2: Temporal profile of soil moisture measurements, daily cumulative rainfall, and 172 cloud fraction in MODIS-Aqua and MODIS-Terra acquisitions over the study site, during the CanEX-SM10 filed campaign.

\section{3.2.Airborne measurements}

175 The L-band dual-polarized airborne brightness temperatures (1.4 GHz) were measured 176 during the campaign at an incidence angle of $40^{\circ}$ and a spatial resolution of 177 approximately $2.25 \mathrm{~km}$ (http://canex-sm10.espaceweb.usherbrooke.ca/; Magagi et al.,

178 2013). These airborne measurements were collected along 16 parallel flight lines

179 covering the entire Kenaston site, by Environment Canada's microwave radiometer 180 mounted on the National Research Council's (NRC) Twin-Otter aircraft at an altitude of

$1812341 \mathrm{~m}$. Land surface infrared temperature $\left(T_{I R}\right)$ was simultaneously measured using a 182 thermal radiometer mounted on the aircraft. The airborne brightness temperature 183 measurements were used in this study to estimate soil moisture at the local scale from the

184 inversion of the L-MEB model (Wigneron et al., 2007). The retrieved soil moisture was 185 compared to the disaggregated soil moisture values. 


\section{3.3.1. SMOS soil moisture data}

189 Version 5.01 of SMOS soil moisture (L2 product), published on 16 March 2012, was

190 used. Details on the SMOS soil moisture algorithm are available in Kerr et al., (2012).

191 We performed quality control and validation of the soil moisture product for our study

192 site (Djamai et al., 2015). Due to the well-known underestimation of SMOS soil

193 moisture; we applied a bias correction to the data to better match ground measurements

194 of soil moisture (Gherboudj et al., 2012; Djamai et al., 2015). Estimates of SMOS soil

195 moisture, at both AM and PM overpasses, on 13 SMOS grid centers located over the

196 study area were used to conduct the disaggregation (Figure 3.a).

\section{3.3.2. MODIS optical and thermal data}

198 The MODIS Terra and Aqua products were downloaded through the NASA Land Data

199 Products and Services website (https://lpdaac.usgs.gov/data_access/reverb). Daily land

200 surface temperature (LST) was extracted from MOD11A1 for Terra and MYD11A1

201 products for Aqua (Figure 3.b). The NDVI index was estimated daily from the red band

202 (band 1) and the near-infrared band (band 2) provided by the MOD09GA and 203 MYD09GA products, respectively for Terra and Aqua (Figure 3.c). Leaf Area Index 204 (LAI) and the surface emissivity datasets were extracted from MCD15A2 and 205 MYD11A1/EM31 MODIS products respectively. LST and NDVI data were used to 206 downscale SMOS soil moisture estimates for both the ascending and descending 207 overpasses, in particular for the estimation of SEE. The surface emissivity and LAI are 208 used by the L-MEB model to invert soil moisture from airborne measurements. In 
209 Figures 3.a and 3.b, the inverse dependence between LST and soil moisture can be

210 clearly seen.

211 To take advantage of the full range of soil evaporative efficiency at $1 \mathrm{~km}$, only cloud-free

212 MODIS products could be used in the downscaling process. Thus, as indicated in Figure

213 2, which presents the temporal profile of the cloud fraction derived from MODIS

214 products, only two cloud-free days were available during the CanEX-SM10 field

215 campaign: DOY 164 and DOY 165. Despite the two days available SMOS data, this

216 study uses a total of 13 SMOS pixels for two overpasses each day. Aircraft and ground

217 soil moisture measurements collected over 60 sampled fields allowed statistical analyses

218 of the results. Moreover, this dataset offers a special opportunity for the evaluation of

219 DISPATCH under extreme soil moisture conditions, which has not previously been

220 investigated

(a)

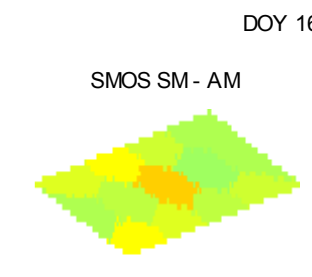

LST - Aqua

b)

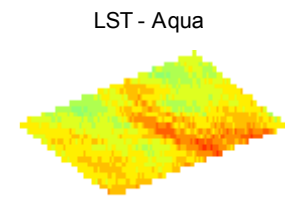

(c)

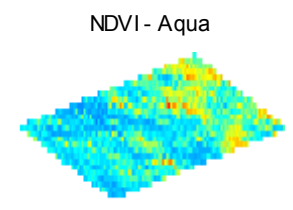

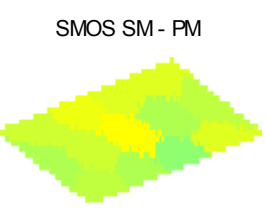

LST - Terra
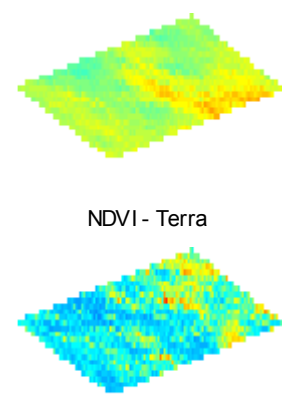

DOY 165
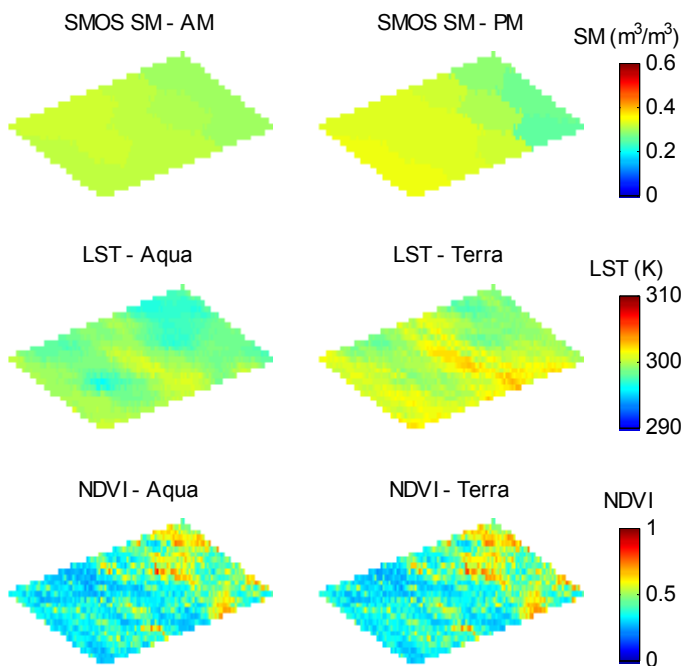

Figure 3: (a) SMOS derived soil moisture, (b) LST and (c) NDVI provided by 


\section{Description of DISPATCH disaggregation algorithm}

228 DISPATCH is based on the spatial relationship between the soil evaporative efficiency

229 (SEE), derived from optical and thermal data, and the top layer soil moisture (SM) at fine

230 scale (Merlin et al., 2012a). It involves three steps: 1) the estimation of SEE; 2) the

231 establishment of a linking model between SEE and SM; and 3) the downscaling of SMOS

232 soil moisture to a finer scale using Equation 1 shown below. Further details of the 233 desegregation method can be found in Merlin et al. (2012a).

$$
S M=<S M>+\frac{\partial S M}{\partial S E E}(S E E-<S E E>)
$$

235 where SM is the disaggregated soil moisture at fine scale (1-km MODIS resolution in this

236 study). SEE is the soil evaporative efficiency estimated using MODIS data at $1-\mathrm{km}$

237 resolution, and $<\mathrm{SEE}>$ is its average value at SMOS pixel scale. $<\mathrm{SM}>$ is the SMOS

238 soil moisture (40-km resolution).

239 SEE is estimated from MODIS optical and thermal data using the model given by 240 Equation 2.

$$
S E E=\frac{T s_{\max }-T s}{T s_{\max }-T s_{\min }}
$$

$242 T s_{\max }$ and $T s_{\min }$ are called "temperature end-members". They represent the maximal

243 and minimal soil temperatures found over the study scale. They are extrapolated from the

244 trapezoidal model (Moran et al., 1994) given by the scatter plot of land surface

245 temperature (LST) versus the vegetation fractional cover $\left(f_{v}\right)$ derived from NDVI data.

$246 T s$ is the soil skin temperature, calculated from MODIS LST and $f_{v}$ as:

$$
T s=\frac{L S T-f_{v} \cdot T_{v}}{1-f_{v}}
$$

248 where $T v$ is the vegetation temperature (Moran et al. 1994). 
249 Equation 2 shows that SEE decreases with an increase in Ts as the soil loses its moisture

250 by evaporation. Thus, it reaches its maximum value $(\mathrm{SEE}=1)$ for $T s=T s_{\min }$ and its

251 minimum value $(\mathrm{SEE}=0)$ at $T s=T s_{\max }$.

252 In the literature, the relationship between SEE and near-surface soil moisture (SM) has

253 been reported as:

254 A linear model (Manabe, 1969): $\quad S M=S M_{p} . S E E$

$255 S M_{p}$ is a parameter estimated by considering the SMOS pixel scale; or

256 A non-linear model (Merlin et al., 2013): $\quad \mathrm{SEE}=\left(\frac{\mathrm{SM}}{\mathrm{SM}_{\mathrm{sat}}}\right)^{\mathrm{p}}$

$257 \mathrm{p}$ is a parameter estimated by considering the SMOS pixel scale, and $S M_{\text {sat }}$ is the 258 saturated soil moisture estimated according to Cosby et al. (1984).

259 5. Methodology

260 The application of the DISPATCH algorithm to SMOS soil moisture and the validation

261 process for the results are schematically presented in Figure 4; details are given in

262 sections 5.1 and 5.2. We made two assumptions in this work. The soil moisture pattern is

263 assumed to be spatially persistent for a few hours after the SMOS overpass to overcome

264 the mismatch between the ground soil moisture measurement time (from $\sim 6$ a.m. to $\sim 11$

265 a.m.) and SMOS overpass times (6 a.m./p.m.) and MODIS Aqua/Terra overpass times (1

266 p.m. and 10 a.m., respectively). If no rainfall occurs between the acquisition times of

267 these measurements, the assumption is generally met. It is also assumed that the land

268 surface temperature derived from MODIS data has a horizontal spatial correlation with

269 the $0-5 \mathrm{~cm}$ soil temperature (Nishida et al., 2003) to overcome the mismatch of the soil

270 moisture and surface temperature sensing depths. 

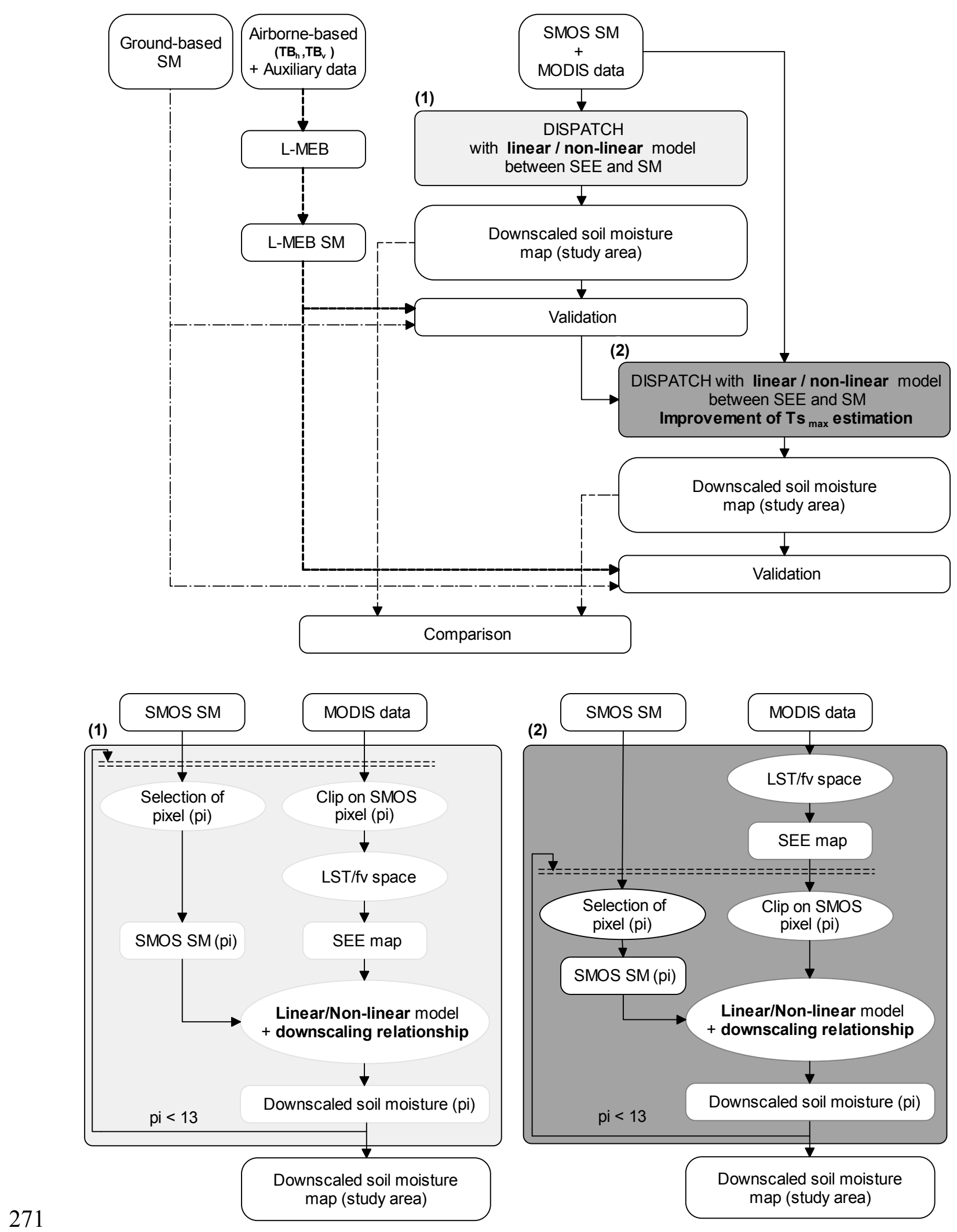

Figure 4: Schematic diagram of the methodology 


\section{5.1. Application of DISPATCH algorithm to SMOS soil moisture}

274 SMOS soil moisture data and cloud-free MODIS images acquired over the Kenaston site

275 during the CanEx-SM10 field experiment were used to estimate soil moisture at $1 \mathrm{~km}$

276 scale from the DISPATCH algorithm (Merlin et al., 2012a). In total, 13 SMOS pixels, 2

277 acquisition times, 2 days, 2 MODIS datasets and 2 linearity modes were considered.

278 To generate daily SEE maps (Equation 2) using MODIS/Aqua and MODIS/Terra 279 datasets, DISPATCH, which was developed under high spatial variability of soil moisture

280 (Merlin et al, 2012b; 2013), is applied to CanEx-SM10's very wet soil conditions. The 281 estimation of the "temperature end-members" was only based on the high-resolution 282 optical/thermal data within each SMOS pixel. Thus, the scatter plots of the vegetation

283 fractional cover $f_{v}$ versus the surface temperature LST and the SEE maps were generated 284 for each SMOS pixel.

285 As a second step, in order to overcome a limitation of DISPATCH encountered for very 286 wet soil conditions: underestimation of $T s_{\max }$, we proposed a simple method to improve 287 the accuracy of $T s_{\max }$ so that it will be representative of a dry soil (water content $\approx$ $\left.2880 \mathrm{~m}^{3} \cdot \mathrm{m}^{3}\right)$. Thus, instead of considering each SMOS pixel independently, the estimation

289 of the "temperature end-members" was based on the high-resolution optical/thermal data 290 within the entire study site. Enlarging the research area allows the consideration of a 291 wider range of surface conditions, namely dry pixels. Thus, instead of considering each

292 SMOS pixel independently, the estimation of the "temperature end-members" was based 293 on the high-resolution optical/thermal data encountered within the entire study site.

294 Therefore, for each of the two MODIS datasets, a unique scatter plot of $f_{v} / \mathrm{LST}$ and a 295 unique SEE map were produced for the entire study area (33 km x $71 \mathrm{~km})$. Considering 
296 that the grid cells of a typical global climate model are about 100 - $300 \mathrm{~km}$ (Salathé et al.,

297 2010; http://scied.ucar.edu/longcontent/climate-modeling), we assume that the uniformity

298 of the atmospheric forcing could be accepted like in the simulations of the Canadian

299 Global Climate Model (CGCM) carried out on a grid of about $415 \mathrm{~km}$ x $415 \mathrm{~km}$ (Flato et

300 al., 2000; Scinocca et al., 2008) and of the Canadian Regional Climate Model (CRCM)

301 whose grid spacing is about $\sim 50 \mathrm{~km}$ (Laprise, 2008).

302 To test the linearity of the relationship between SEE and SM (Equation 2) under very wet

303 soil conditions, both linear and non-linear models were used in Equation 1 to generate

304 soil moisture at $1-\mathrm{km}$ scale.

\section{$305 \quad$ 5.2. Validation with ground-based data}

306 For validation purposes, we compared the 1-km downscaled soil moisture to the ground-

307 based soil moisture data collected during the field campaign. First, ground soil moisture

308 data were calculated for each field as the average of the contained point measurements.

309 Only SMOS day-time overpass data were used because of the constraints imposed by the

310 field data acquisition times.

\section{5.3. Comparison to L-MEB inversion}

312 The SMOS downscaled soil moisture was also compared to the soil moisture estimated

313 by inverting the L-MEB model. We used the L-band airborne brightness temperature

$314\left(T b_{h}, T b_{v}\right)$ measurements. The main unknowns in the model were the soil temperature

315 (Ts) and optical thickness $(\tau)$. Ts was estimated from Equation 6, where $T_{I R}$ is the

316 infrared temperature measured by the thermal radiometer mounted on board the Twin

317 Otter aircraft, and $e$ is the soil emissivity which was extracted from the MODIS data. 
$319 \tau$ was estimated from the MODIS LAI product according to Equation 7 (Kerr et al., 320 2012):

$$
\tau=b_{v} . L A I
$$

322 where $b_{v}$ is an empirical parameter equal to 0.06 for low vegetation.

323 First $T b_{h}, T b_{v}$ and $T s$ were re-sampled to the MODIS grid ( $\left.1 \mathrm{~km} \times 1 \mathrm{~km}\right)$. Then, an

324 iterative process was used to determine the soil moisture value that minimizes the root

325 mean square error (RMSE) between the modeled and the measured brightness

326 temperatures at $\mathrm{H}$ and $\mathrm{V}$ polarizations. Finally, the retrieved soil moisture values at 1-km

327 resolution using L-MEB were compared to the downscaled soil moisture using the

328 DISPATCH algorithm.

\section{5.4. Sensitivity analysis}

330 As described above, the disaggregation method is based on the soil evaporative 331 efficiency, which in turn depends on temperature end-members. For wet soil conditions,

332 the estimation of the dry edge $T s_{\max }$ is not obvious. We conducted a sensitivity analysis

333 to understand the effect of a small variation of $T s_{\max }$ in the extrapolated value on the

334 downscaled soil moisture, in order to evaluate the stability of the model under wet soil

335 conditions. Thus, the partial derivative of the downscaling relationship (Equation 1) with

336 respect to $T s_{\max }\left(\mathrm{dSM} / \mathrm{d} T s_{\max }\right)$ was computed for different soil temperatures between

$337 T s_{\min }$ and $T s_{\max }$. 


\section{Results}

\subsection{Disaggregation of SMOS soil moisture data}

343 Soil moisture results obtained from DISPATCH downscaling algorithm (Merlin et al.,

344 2012a) are presented and validated using ground measurements of soil moisture.

345 Comparison of the results with L-MEB derived soil moisture using airborne data is also

346 conducted. It is followed by a sensitivity analysis of the downscaled soil moisture

347 to $T s_{\max }$.

\subsubsection{Soil moisture maps}

349 The maps of 1-km downscaled soil moisture for DOY 164 and 165 for the day-time and

350 the night-time overpasses obtained from SMOS/MODIS (Terra and Aqua) data and the

351 use of linear and non-linear models between SEE and SM are shown in Figure 5.a.

352 The results from the linear and non-linear models better captured the spatial patterns of

353 soil moisture at fine scale (Figure 5.a) than the coarse resolution SMOS data (Figure 3.a).

354 In accordance with the topography of the study site, very wet soils were identified in the

355 north-eastern and the central parts of the site. The decrease in soil moisture observed

356 from DOY 164 to DOY 165 (successive no rainy days), following a rainy period (before

357 164), was effectively captured by SMOS and was also reproduced at higher resolution.

358 Table 1 shows that the different downscaled soil moisture maps have a very similar

359 spatial mean value $\left(\approx 0.33 \mathrm{~m}^{3} / \mathrm{m}^{3}\right)$. This explains the zero biases generally found

360 between these maps (Table 2). However, the maps derived using the linear model have

361 higher spatial dynamics $\left(\right.$ std $\left.\approx 0.12 \mathrm{~m}^{3} / \mathrm{m}^{3}\right)$ than those derived from the non-linear

$362 \operatorname{model}\left(\right.$ std $\left.\approx 0.06 \mathrm{~m}^{3} / \mathrm{m}^{3}\right)$. This remark can be also noticed through the Figure 5.a. 
363 The downscaled soil moisture maps derived from the SMOS/Aqua combination and

364 SMOS/Terra combination show very similar spatial patterns (Figure 5.a). Table 2

365 presents the statistics for the two datasets: correlation coefficients from 0.72 to 0.91 ,

366 RMSE values from 0.01 to $0.05 \mathrm{~m}^{3} / \mathrm{m}^{3}$, zero biases, and slopes varying from 0.68 to 0.88 .

367 Analyses of the spatial difference in soil moisture maps between the SMOS/Aqua

368 combination and SMOS/Terra combination were also conducted (Figure 5.b). The results

369 indicate that SMOS/Aqua and SMOS/Terra combinations are closer for DOY 164

370 compared to DOY 165 and much more for the non-linear model compared to the linear

371 model.

372 High spatial correlation coefficients (R from 0.87 to 0.94 , Table 2) were also obtained

373 between the downscaled soil moisture maps using the linear and non-linear models.

374 However, Table 2 shows higher RMSE values $\left(\sim 0.06 \mathrm{~m}^{3} / \mathrm{m}^{3}\right)$ and lower slopes $(\sim 0.5)$

375 between the soil moisture maps derived from the two models, compared values found

376 when comparing maps derived from the SMOS/Aqua and SMOS/Terra combinations.

377 Compared to Figure 5.a, the spatial difference in soil moisture maps between the linear

378 and non-linear models (Figure 5.c) shows the highest values over the driest and the 379 wettest pixels. 


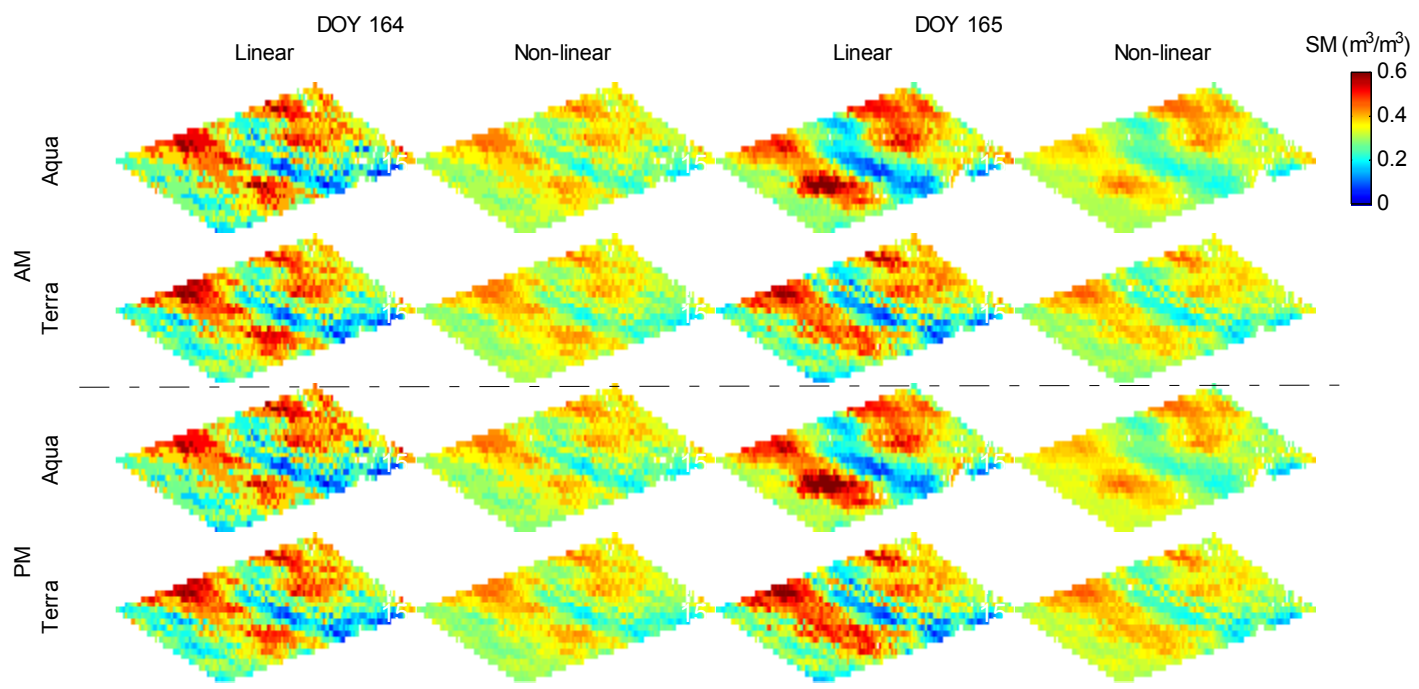

Figure 5.a: Downscaled soil moisture provided by SMOS/Terra and SMOS/Aqua combinations, linear and non-linear models, on DOY 164 and 165, ascending (AM) and descending (PM) SMOS overpasses.

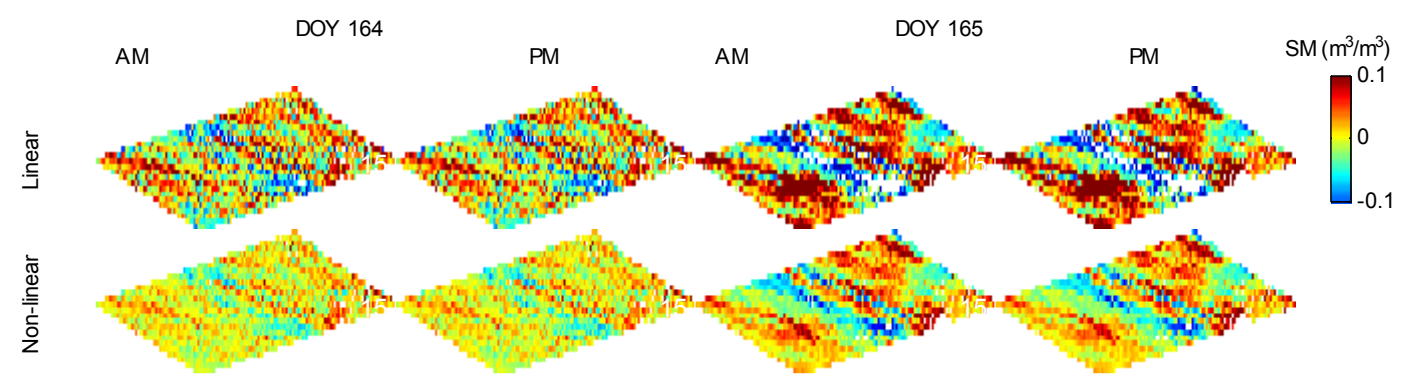

Figure 5.b: Spatial difference in soil moisture maps between SMOS/Aqua combination and SMOS/Terra combination using the linear and non-linear models.

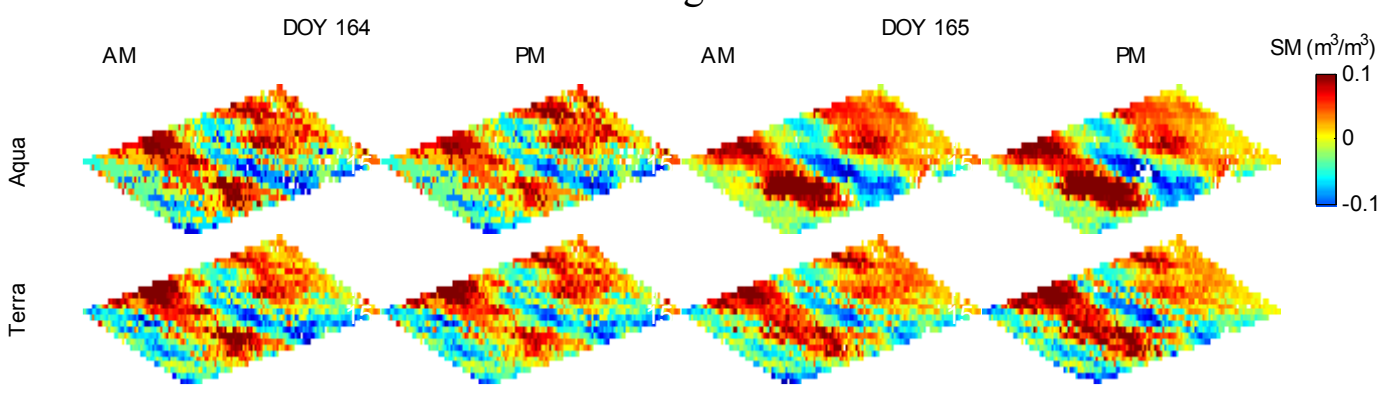

Figure 5.c: Spatial difference in soil moisture maps between the linear and non-linear models for both SMOS/Aqua and SMOS/Terra combinations. 
Table 1: Mean, standard deviation, minimum and maximum values of the downscaled soil moisture maps.

400

401

402

403

404

405

410 obtained from SMOS/Terra and SMOS/Aqua derived soil moisture maps. They show low

411 biases for both linear and non-linear models (from -0.01 to $0.04 \mathrm{~m}^{3} / \mathrm{m}^{3}$ ) and slightly

412 better correlation coefficients with the linear model (from 0.50 to 0.60 for ground-based

Table 2: Correlation coefficients, RMSE, bias and slope values between the downscaled soil moisture maps estimated from (a) MODIS Aqua and MODIS Terra data using the linear and non-linear models, and (b) the linear and non-linear models for both SMOS/Aqua and SMOS/Terra combinations

\begin{tabular}{|c|c|c|c|c|c|c|c|c|c|c|c|}
\hline \multicolumn{7}{|c|}{ (a) Aqua/Terra } & \multicolumn{5}{|c|}{ (b) Linear/non-linear } \\
\hline$\overline{\mathrm{DOY}}$ & Time & Model & $\mathrm{R}$ & $\begin{array}{c}\text { RMSE } \\
\left(\mathrm{m}^{3} / \mathrm{m}^{3}\right)\end{array}$ & $\begin{array}{c}\text { Bias } \\
\left(\mathrm{m}^{3} / \mathrm{m}^{3}\right)\end{array}$ & Slope & Sensor & $\mathrm{R}$ & $\begin{array}{l}\text { RMSE } \\
\left(\mathrm{m}^{3} / \mathrm{m}^{3}\right)\end{array}$ & $\begin{array}{c}\text { Bias } \\
\left(\mathrm{m}^{3} / \mathrm{m}^{3}\right)\end{array}$ & Slope \\
\hline 164 & AM & Linear & 0.86 & 0.02 & 0.00 & 0.86 & Aqua & 0.93 & 0.06 & 0.00 & 0.48 \\
\hline 164 & PM & Linear & 0.86 & 0.02 & 0.00 & 0.86 & Aqua & 0.94 & 0.06 & 0.00 & 0.51 \\
\hline 165 & $\mathrm{AM}$ & Linear & 0.73 & 0.05 & -0.01 & 0.68 & Aqua & 0.94 & 0.06 & -0.01 & 0.50 \\
\hline 165 & PM & Linear & 0.72 & 0.05 & -0.01 & 0.68 & Aqua & 0.87 & 0.07 & -0.01 & 0.47 \\
\hline 164 & $\mathrm{AM}$ & Non-linear & 0.90 & 0.02 & 0.00 & 0.88 & Terra & 0.93 & 0.06 & 0.00 & 0.49 \\
\hline 164 & PM & Non-linear & 0.91 & 0.01 & 0.00 & 0.88 & Terra & 0.94 & 0.06 & 0.00 & 0.51 \\
\hline 165 & $\mathrm{AM}$ & Non-linear & 0.76 & 0.05 & 0.00 & 0.75 & Terra & 0.93 & 0.05 & 0.00 & 0.54 \\
\hline 165 & PM & Non-linear & 0.80 & 0.04 & 0.00 & 0.76 & Terra & 0.88 & 0.06 & 0.00 & 0.50 \\
\hline
\end{tabular}

\subsubsection{Validation and comparison}

The scatter plots of the downscaled soil moisture versus the ground-based soil moisture and the L-MEB derived soil moisture are presented in Figure 6 and Figure 7, respectively. They indicate that, for a given model, comparable statistical results were 
413 data; from 0.73 to 0.80 for L-MEB derived soil moisture) compared to the non-linear

414 model (from 0.37 to 0.51 for ground-based data; from 0.70 to 0.78 for L-MEB derived

415 soil moisture). The low correlation with ground-based data might be the result of the low

416 variability of soil moisture between the measured fields or the spatial representativeness

417 of in situ measurements at the downscaling resolution.

418 To check the significance of the correlation coefficients found between the soil moisture

419 datasets, the Pearson H0 statistical test was applied. The null hypothesis "H0: X and Y

420 are linked (X and $\mathrm{Y}$ are the two soil moisture datasets)" was considered with different

421 thresholds. The results indicated that the correlation between the downscaled soil

422 moisture and L-MEB derived soil moisture was significant at $p<0.05$. But the

423 correlation between the downscaled soil moisture and the ground-based measurements

424 was significant only when $\mathrm{p}<0.10$.

425 In terms of RMSE, the downscaled soil moisture data resulting from the non-linear model

426 (RMSE $\approx 0.04 \mathrm{~m}^{3} / \mathrm{m}^{3}$, compared to both ground-based data and L-MEB derived soil

427 moisture) are more accurate than those from the linear model (RMSE $\approx 0.08 \mathrm{~m}^{3} / \mathrm{m}^{3}$ ).

428 Furthermore, in contrast to the non-linear model, both Figures 6 and 7 show that the

429 downscaled soil moisture values resulting from the linear model vary over a broader

430 range (from about 0 to $0.50 \mathrm{~m}^{3} / \mathrm{m}^{3}$ ) compared to the ground-based data $(0.25$ to 0.45

$\left.431 \mathrm{~m}^{3} / \mathrm{m}^{3}\right)$ and the L-MEB derived soil moisture $\left(0.18\right.$ to $\left.0.5 \mathrm{~m}^{3} / \mathrm{m}^{3}\right)$. As a consequence, a

432 slope varying from about 1.4 to 1.9 was observed for the scatter plots using the linear

433 model, while it was close to 1 (about 0.6 to 0.9 ) for the non-linear model.

434 These results indicate that under very wet soil conditions, the non-linear model leads to

435 better results than the linear model. This may be due to the fact that the estimated $T s_{\max }$ 
436 could be lower than its real value, given the difficulty of finding a dry surface inside the

437 SMOS pixel to calibrate it properly. Consequently, the linear model linearly stretches the

438 soil moisture values over a wider range than in reality, thus giving scatter plots

439 characterized by pronounced slopes $(>1.4)$ as shown in Figures 6 and 7. The non-linear

440 model is able to compensate for systematic underestimation of $T s_{\max }$ under generally

441 wet conditions within the SMOS pixel. To further investigate the role of $\mathrm{Ts}_{\max }$ on the

442 downscaled soil moisture, a sensitivity analysis was conducted.

DOY 164

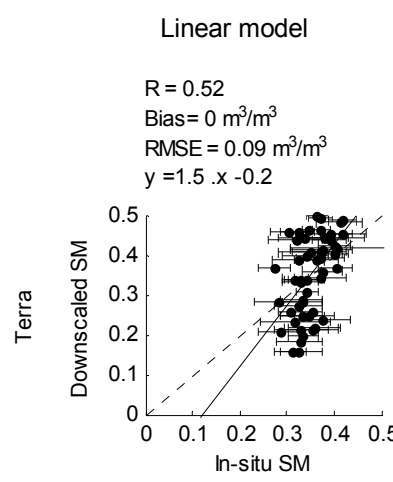

$$
\mathrm{R}=0.5
$$

Bias $=0.01 \mathrm{~m}^{3} / \mathrm{m}^{3}$ RMSE $=0.09 \mathrm{~m}^{3} / \mathrm{m}^{3}$ $y=1.4 . x-0.1$

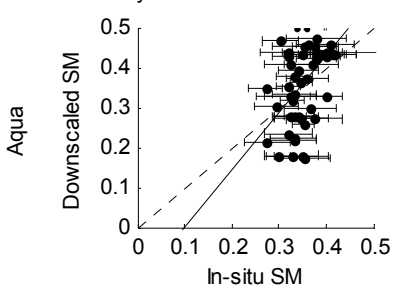

Non-linear model

$R=0.4$

Bias $=-0.01 \mathrm{~m}^{3} / \mathrm{m}^{3}$ RMSE $=0.05 \mathrm{~m}^{3} / \mathrm{m}^{3}$ $y=0.6 . x+0.1$

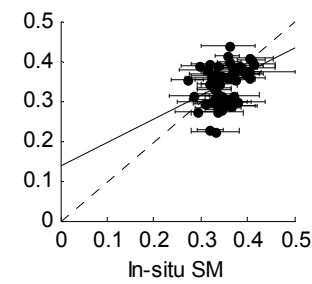

$\mathrm{R}=0.37$

Bias $=0 \mathrm{~m}^{3} / \mathrm{m}^{3}$ RMSE $=0.05 \mathrm{~m}^{3} / \mathrm{m}^{3}$ $y=0.6 . x+0.2$

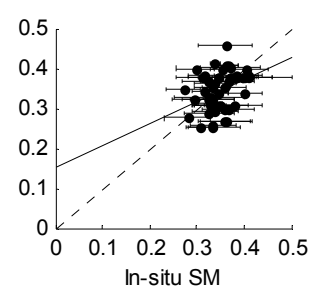

DOY 165
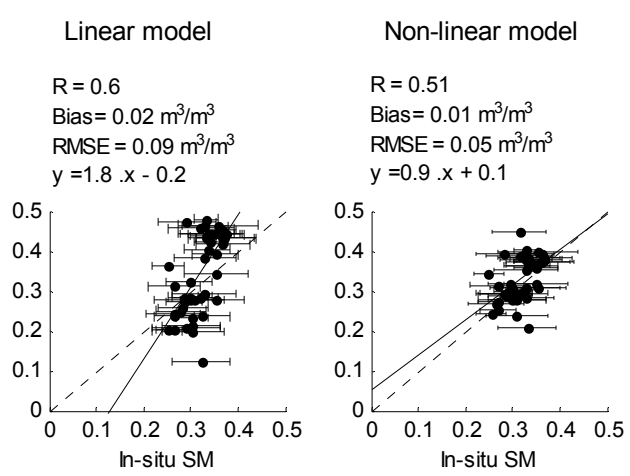

$$
\mathrm{R}=0.6
$$

Bias $=0.04 \mathrm{~m}^{3} / \mathrm{m}^{3}$ RMSE $=0.10 \mathrm{~m}^{3} / \mathrm{m}^{3}$ $y=1.9 . x-0.3$

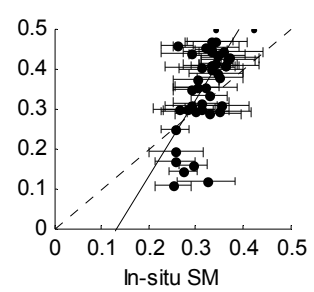

$R=0.5$

Bias $=0.01 \mathrm{~m}^{3} / \mathrm{m}^{3}$ RMSE $=0.04 \mathrm{~m}^{3} / \mathrm{m}^{3}$ $y=0.8 . x+0.1$

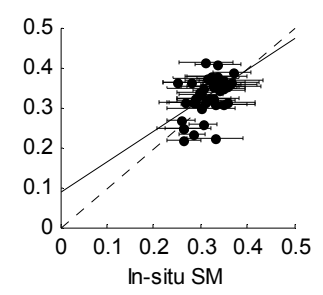

Figure 6: Day-time downscaled soil moisture compared to in situ soil moisture. 
DOY 164
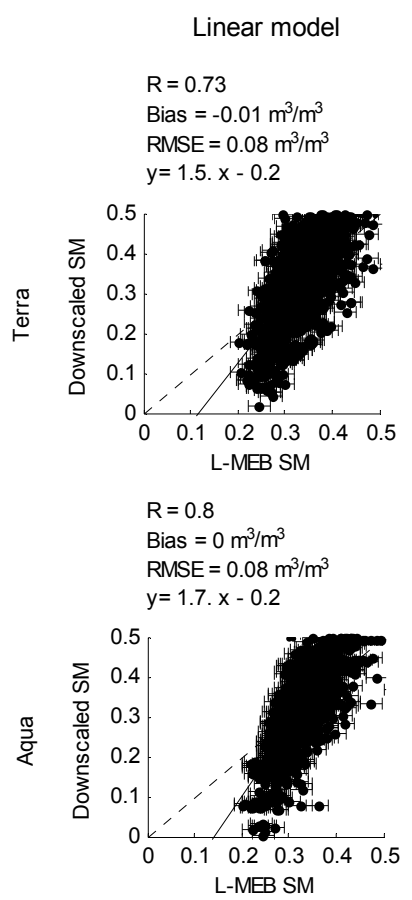

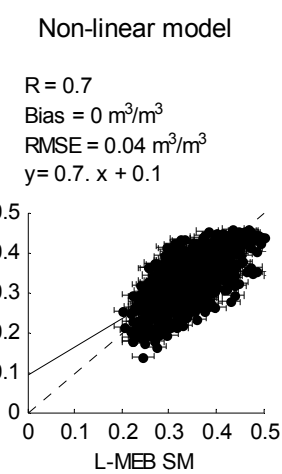

$$
\mathrm{R}=0.78
$$

Bias $=0 \mathrm{~m}^{3} / \mathrm{m}^{3}$ RMSE $=0.04 \mathrm{~m}^{3} / \mathrm{m}^{3}$ $y=0.8 . x+0.1$

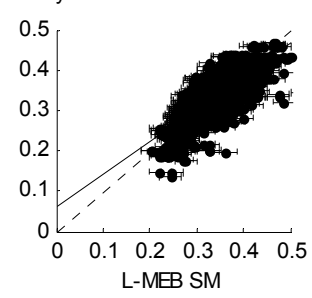

DOY 165
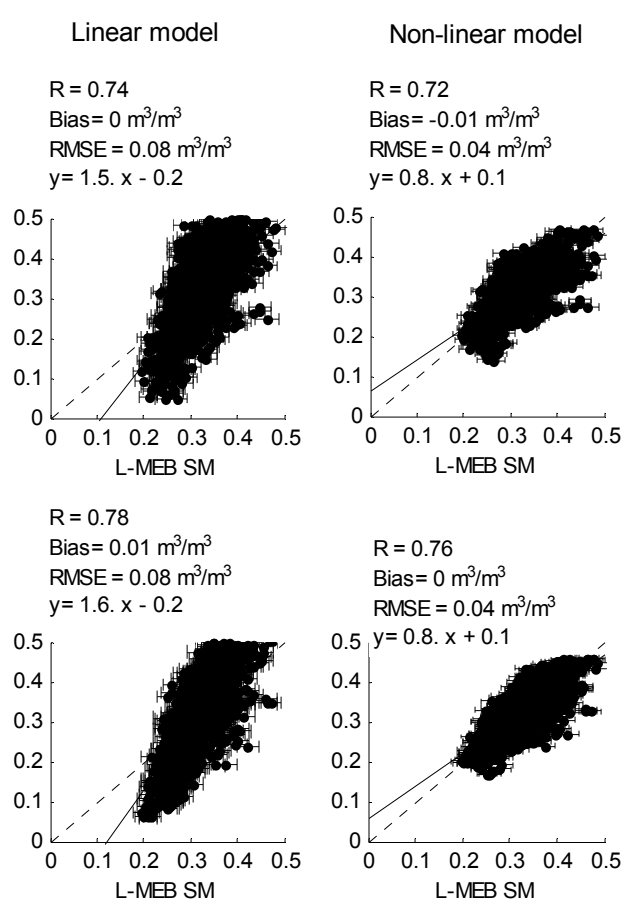

Figure 7: Day-time downscaled soil moisture compared to L-MEB derived soil moisture.

\subsubsection{Sensitivity study}

449 Figure 8 presents $\mathrm{dSM} / \mathrm{dTsmax}$ as a function of $T s_{\max }$ for two selected SMOS pixels

450 located within the study site. The vertical bold and dotted lines (not presented when

451 lower than the origin of the $\mathrm{x}$ axis) represent respectively the extrapolated $T s_{\max }$ and

$452 T s_{\min }$ values (Section 6.1.1), referred here as $T s_{\max -\bmod }$ and $T s_{\min -\bmod }$. Results show

453 that the sensitivity of the downscaled soil moisture to $T s_{\max }$ decreases with an increase

454 of $T s_{\max }-T s_{\min }$ and is highly related to the model used to express the relationship

455 between SEE and SM.

456 For the linear model, the sensitivity is higher than $0.10 \frac{\mathrm{m}^{3}}{\mathrm{~m}^{3}} / \mathrm{K}$ for a value of $\mathrm{Ts}_{\max -\bmod }$

457 close to $\mathrm{Ts}_{\min -\bmod }$ (DGG ID: 147227); it becomes lower $\left(<0.04 \frac{\mathrm{m}^{3}}{\mathrm{~m}^{3}} / \mathrm{K}\right)$ otherwise 458 (DGG ID: 147225). For the non-linear model, the downscaled soil moisture was more 
459 stable as a function of $\mathrm{Ts}_{\max }$. The sensitivity is about $0.05 \frac{\mathrm{m}^{3}}{\mathrm{~m}^{3}} / \mathrm{K}$ for a value of $460 \quad \mathrm{Ts}_{\max -\bmod }$ close to $\mathrm{Ts}_{\min -\bmod }$, and about $0.01 \frac{\mathrm{m}^{3}}{\mathrm{~m}^{3}} / \mathrm{K}$ otherwise.

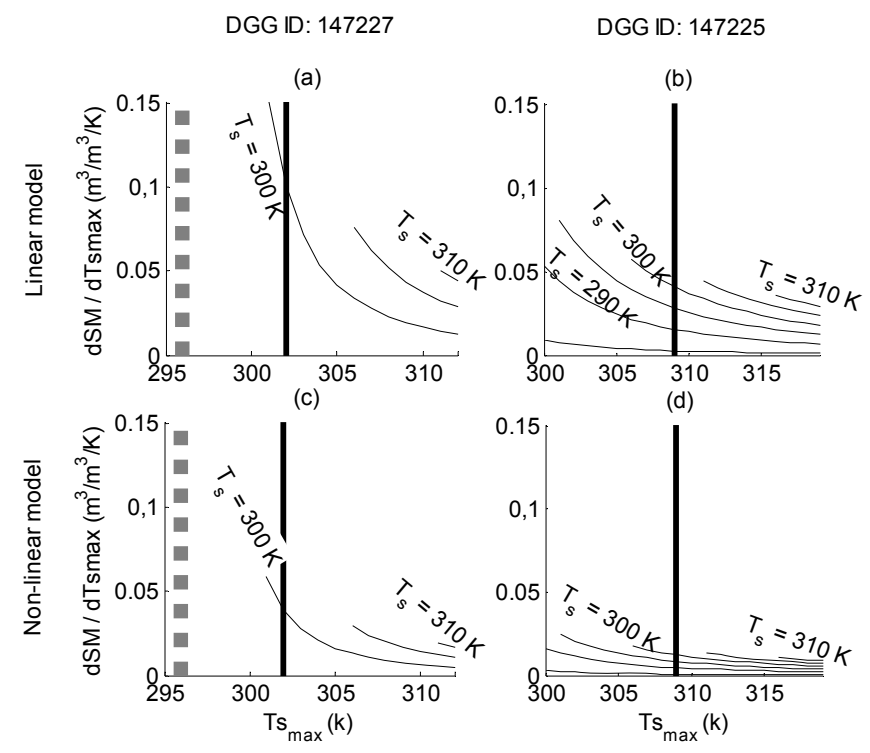

463 Under conditions of low spatial variability of soil moisture, these results showed that the

464 downscaled soil moisture is significantly sensitive to Tsmax, and much more so using the

465 linear model. Subsequently, we presented the possibility of improving the estimated

466 Tsmax using the neighboring soil conditions. The idea is to determine the Tsmax value more

467 representative of a dry soil (water content $\approx 0 \mathrm{~m}^{3} / \mathrm{m}^{3}$ ) in order to reduce the dependence 468 of the downscaled soil moisture on Tsmax.

\section{6.2. Improvement of $\mathrm{Ts}_{\max }$}

470 Here, we proposed to improve the already estimated $\mathrm{Ts}_{\max }$ value (Section 5.1). Soil 471 moisture results obtained from DISPATCH downscaling algorithm using the 472 improved $T s_{\max }$ value are presented and validated with ground measurements of soil 473 moisture. Comparison of the results with L-MEB derived soil moisture using airborne 
474 data is also conducted. It is followed by a sensitivity analysis to evaluate the stability of

475 the downscaled soil moisture to the improved value of $T s_{\max }$.

\subsubsection{Soil moisture maps}

477 The maps of 1-km downscaled soil moisture using the improved value of $T s_{\max }$ are 478 shown in Figure 9.a. The same observations previously made (Section 6.1.1) can be 479 repeated here for the spatial distribution of soil moisture (Figure 9.a and Table 3) and the 480 statistics between the different maps (Table 4). Nevertheless, although Tables 1 and 3 481 show a similar spatial average for the downscaled soil moisture maps $\left(\approx 0.33 \mathrm{~m}^{3} / \mathrm{m}^{3}\right)$, 482 lower spatial variability are observed in Figure 9.a compared to Figure 5.a (in Table 3, 483 std $\leq 0.07 \mathrm{~m}^{3} / \mathrm{m}^{3}$ and std $\leq 0.03 \mathrm{~m}^{3} / \mathrm{m}^{3}$, respectively for the linear and non-linear

484 models). As for the spatial difference in soil moisture maps, obtained from SMOS/Aqua 485 and SMOS/Terra combinations and from the linear and non-linear models, the same 486 observations previously made for Figures 5.b and 5.c can also be repeated (Figures 9.b 487 and 9.c). However, lower linear/non-linear differences were noted for DOY 165 488 compared to DOY 164, especially for maps derived from the SMOS/Aqua combination.

489 From the analysis of the results, it appears that the use of the improved value of $490 T s_{\max }$ does not modify the spatial pattern of soil moisture over the study site (i.e., the 491 location of the wettest and driest pixels); it only changes the absolute value of soil 492 moisture at fine scale. 
493

494

495

496

497

498

499

500

501

502

503

504

505

506

507

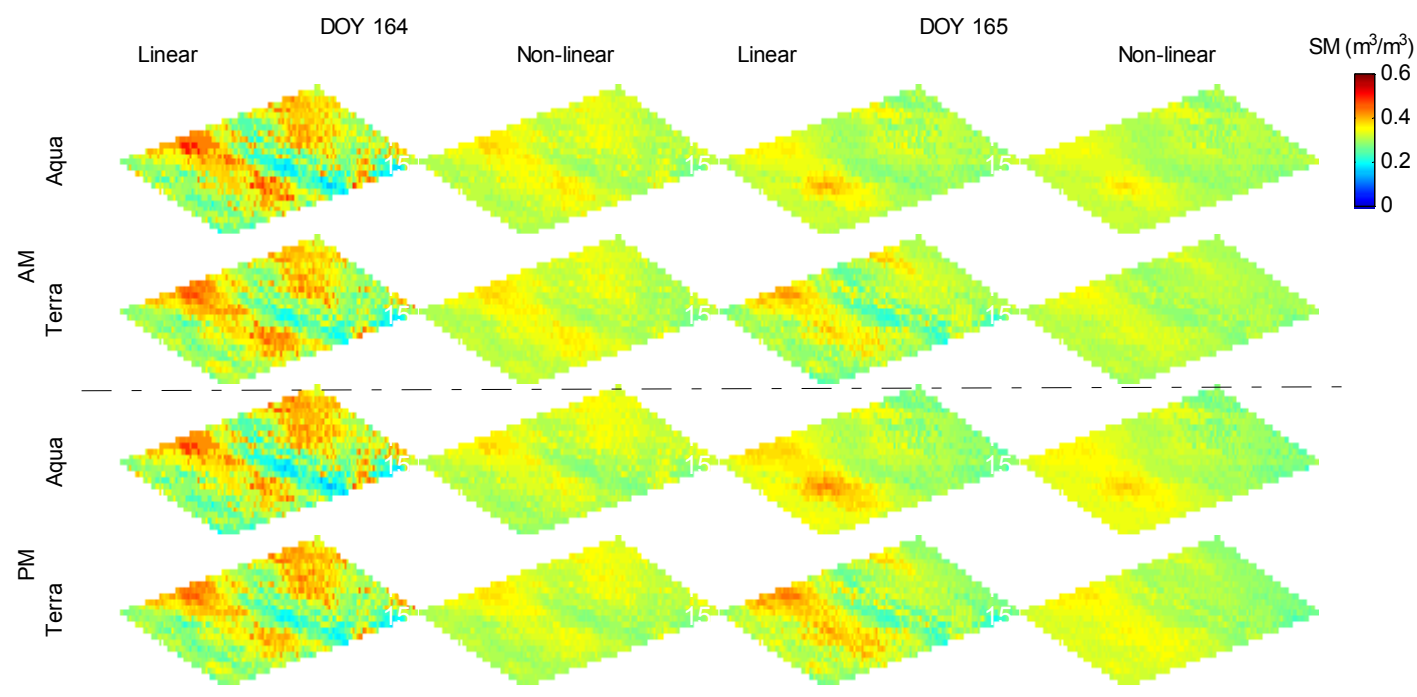

Figure 9.a: Downscaled soil moisture from the use of the improved value of $T s_{\max }$, SMOS/Aqua and SMOS/Terra combinations, linear and non-linear models, day-time and night-time SMOS overpasses on DOY 164 and 165.

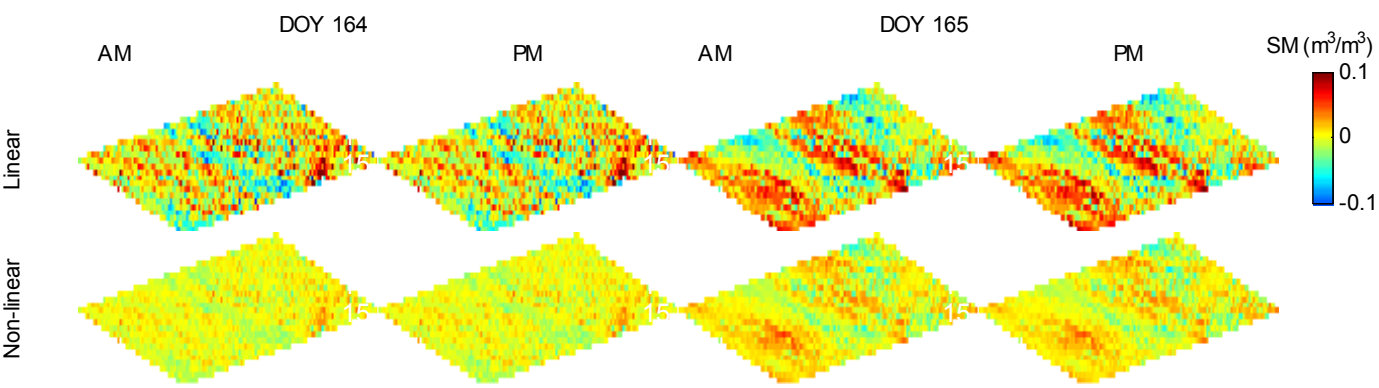

Figure 9.b: Spatial difference in soil moisture maps between SMOS/Aqua combination and SMOS/Terra combination from the use of the linear and non-linear models and the improved value of $T s_{\max }$.

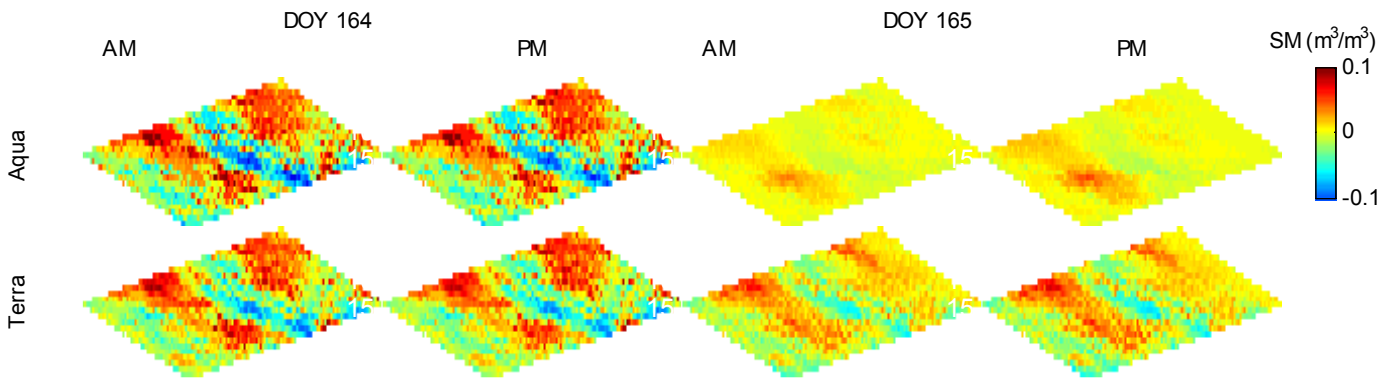

Figure 9.c: Spatial difference in soil moisture maps between the linear and non-linear models for both SMOS/Aqua and SMOS/Terra combinations and the use of the improved value of $\left.T s_{\max }\right)$. 
Table 3: Mean, standard deviation, minimum and maximum values of the downscaled soil moisture maps using the improved value of $T s_{\max }$.

\begin{tabular}{l|l|l|cccc|cccc}
\hline \multicolumn{2}{l|}{} & \multicolumn{6}{c|}{ Aqua } & \multicolumn{4}{c}{ Terra } \\
\hline Model & DOY & Time & $\begin{array}{c}\text { Mean } \\
\left(\mathrm{m}^{3} / \mathrm{m}^{3}\right)\end{array}$ & $\begin{array}{c}\text { Std. } \\
\left(\mathrm{m}^{3} / \mathrm{m}^{3}\right)\end{array}$ & $\begin{array}{c}\text { Min } \\
\left(\mathrm{m}^{3} / \mathrm{m}^{3}\right)\end{array}$ & $\begin{array}{c}\text { Max } \\
\left(\mathrm{m}^{3} / \mathrm{m}^{3}\right)\end{array}$ & $\begin{array}{c}\text { Mean } \\
\left(\mathrm{m}^{3} / \mathrm{m}^{3}\right)\end{array}$ & $\begin{array}{c}\text { Std. } \\
\left(\mathrm{m}^{3} / \mathrm{m}^{3}\right)\end{array}$ & $\begin{array}{c}\text { Min } \\
\left(\mathrm{m}^{3} / \mathrm{m}^{3}\right)\end{array}$ & $\begin{array}{c}\text { Max } \\
\left(\mathrm{m}^{3} / \mathrm{m}^{3}\right)\end{array}$ \\
\hline Linear & 164 & $\mathrm{AM}$ & 0.33 & 0.07 & 0.14 & 0.50 & 0.33 & 0.06 & 0.15 & 0.48 \\
Linear & 164 & $\mathrm{PM}$ & 0.32 & 0.07 & 0.15 & 0.49 & 0.32 & 0.06 & 0.16 & 0.48 \\
Linear & 165 & $\mathrm{AM}$ & 0.32 & 0.03 & 0.25 & 0.42 & 0.31 & 0.04 & 0.20 & 0.43 \\
Linear & 165 & $\mathrm{PM}$ & 0.32 & 0.04 & 0.23 & 0.45 & 0.32 & 0.04 & 0.19 & 0.45 \\
Non-linear & 164 & $\mathrm{AM}$ & 0.33 & 0.02 & 0.25 & 0.39 & 0.33 & 0.02 & 0.25 & 0.38 \\
Non-linear & 164 & $\mathrm{PM}$ & 0.32 & 0.02 & 0.25 & 0.38 & 0.32 & 0.02 & 0.26 & 0.38 \\
Non-linear & 165 & $\mathrm{AM}$ & 0.32 & 0.02 & 0.26 & 0.38 & 0.31 & 0.02 & 0.25 & 0.36 \\
Non-linear & 165 & $\mathrm{PM}$ & 0.32 & 0.03 & 0.23 & 0.40 & 0.32 & 0.03 & 0.22 & 0.37 \\
\hline
\end{tabular}

Table 4: Correlation coefficients, RMSE, bias and slope values between the downscaled soil moisture maps estimated from the use of the improved value of $T s_{\max }$ and (a) MODIS Aqua and MODIS Terra data using the linear and the -linear models, and (b) the linear and non-linear models for both SMOS/Aqua and SMOS/Terra combinations.

\begin{tabular}{|c|c|c|c|c|c|c|c|c|c|c|c|}
\hline \multicolumn{7}{|c|}{ (a) Aqua/Terra } & \multicolumn{5}{|c|}{ (b) Linear/non-linear } \\
\hline DOY & Time & Model & $\mathrm{R}$ & $\begin{array}{c}\text { RMSE } \\
\left(\mathrm{m}^{3} / \mathrm{m}^{3}\right)\end{array}$ & $\begin{array}{c}\text { Bias } \\
\left(\mathrm{m}^{3} / \mathrm{m}^{3}\right)\end{array}$ & Slope & Sensor & $\mathrm{R}$ & $\begin{array}{c}\text { RMSE } \\
\left(\mathrm{m}^{3} / \mathrm{m}^{3}\right) \\
\end{array}$ & $\begin{array}{c}\text { Bias } \\
\left(\mathrm{m}^{3} / \mathrm{m}^{3}\right)\end{array}$ & Slope \\
\hline 164 & $\mathrm{AM}$ & Linear & 0.85 & 0.04 & 0.00 & 0.75 & Aqua & 0.94 & 0.05 & 0.00 & 0.31 \\
\hline 164 & PM & Linear & 0.86 & 0.03 & 0.00 & 0.76 & Aqua & 0.98 & 0.04 & 0.00 & 0.34 \\
\hline 165 & AM & Linear & 0.64 & 0.04 & 0.00 & 0.69 & Aqua & 0.99 & 0.01 & 0.00 & 0.73 \\
\hline 165 & PM & Linear & 0.62 & 0.04 & 0.00 & 0.73 & Aqua & 0.98 & 0.01 & 0.00 & 0.79 \\
\hline 164 & $\mathrm{AM}$ & Non-linear & 0.89 & 0.01 & 0.00 & 0.86 & Terra & 0.94 & 0.04 & 0.00 & 0.34 \\
\hline 164 & PM & Non-linear & 0.88 & 0.01 & 0.00 & 0.82 & Terra & 0.98 & 0.04 & 0.00 & 0.36 \\
\hline 165 & $\mathrm{AM}$ & Non-linear & 0.67 & 0.02 & 0.00 & 0.48 & Terra & 0.96 & 0.02 & 0.00 & 0.41 \\
\hline 165 & PM & Non-linear & 0.84 & 0.02 & 0.00 & 0.73 & Terra & 0.85 & 0.03 & 0.00 & 0.49 \\
\hline
\end{tabular}

520 Figures 10 and 11 present the scatter plots of the downscaled soil moisture versus the 521 ground-based soil moisture and the L-MEB derived soil moisture, respectively. They 522 show low biases for both the linear and non-linear models (from -0.01 to $0.01 \mathrm{~m}^{3} / \mathrm{m}^{3}$ ), 523 comparable RMSE values (from 0.03 to $0.05 \mathrm{~m}^{3} / \mathrm{m}^{3}$ ), slightly better correlation 524 coefficients with the linear model and better correlation between the downscaled results 
525 and the L-MEB derived soil moisture ( $\mathrm{R}$ from 0.49 to 0.79 ) than the ground data ( $\mathrm{R}$ from

$526 \quad 0.30$ to 0.52$)$.

527 However, compared to the results shown in Figures 6 and 7, the range of the downscaled

528 soil moisture is narrower (Figures 10 and 11). For the linear model, it is similar to that of

529 the ground data, except for SMOS/Aqua derived soil moisture on DOY 165. As a result,

530 using the improved $T s_{\max }$ value under very wet soil conditions leads to a slope varying

531 from 0.6 to 1 , with the linear model. For the non-linear model, weak results are obtained

532 (slopes from 0.2 to 0.3 ), in contrast to the results previously found (Section 6.1.2).

DOY 164
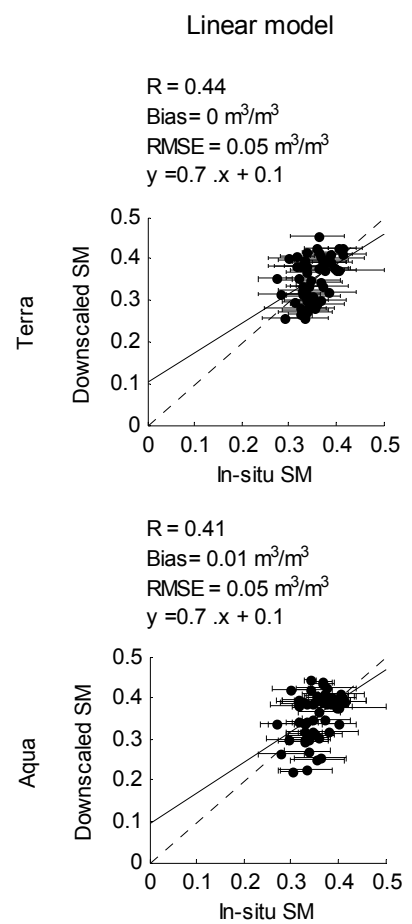

Non-linear model

$R=0.34$

Bias $=-0.01 \mathrm{~m}^{3} / \mathrm{m}^{3}$ RMSE $=0.03 \mathrm{~m} / \mathrm{m}^{3}$ $y=0.2 \cdot x+0.3$

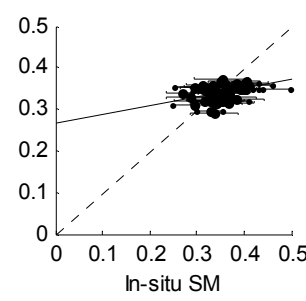

$$
\begin{aligned}
& R=0.3 \\
& \text { Bias }=-0.01 \mathrm{~m}^{3} / \mathrm{m}^{3} \\
& \text { RMSE }=0.03 \mathrm{~m}^{3} / \mathrm{m}^{3} \\
& y=0.2 . x+0.3
\end{aligned}
$$

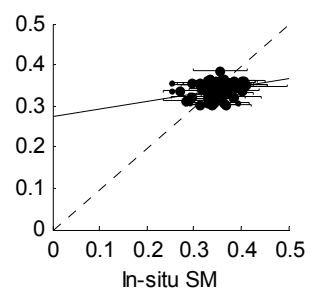

DOY 165
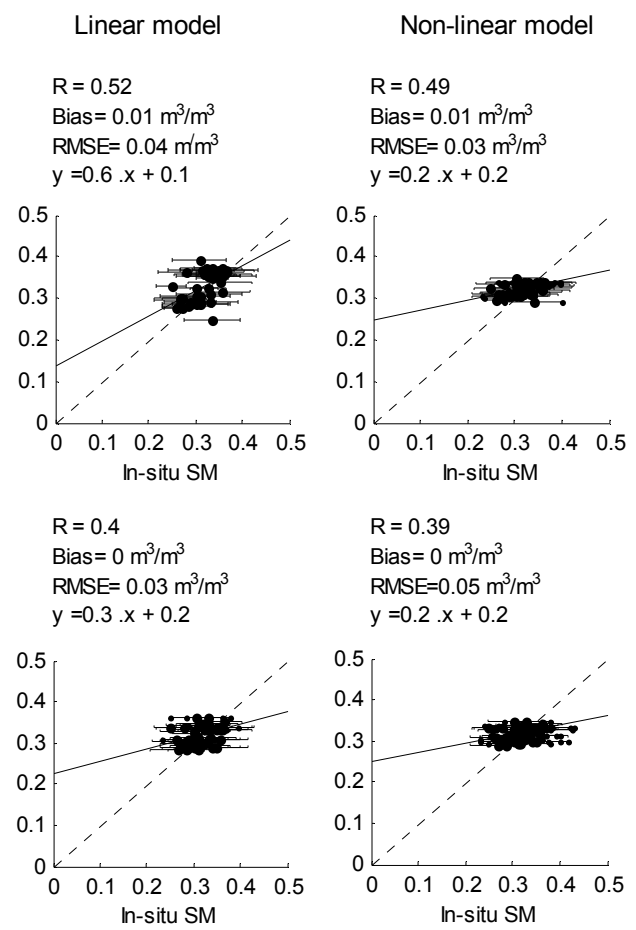

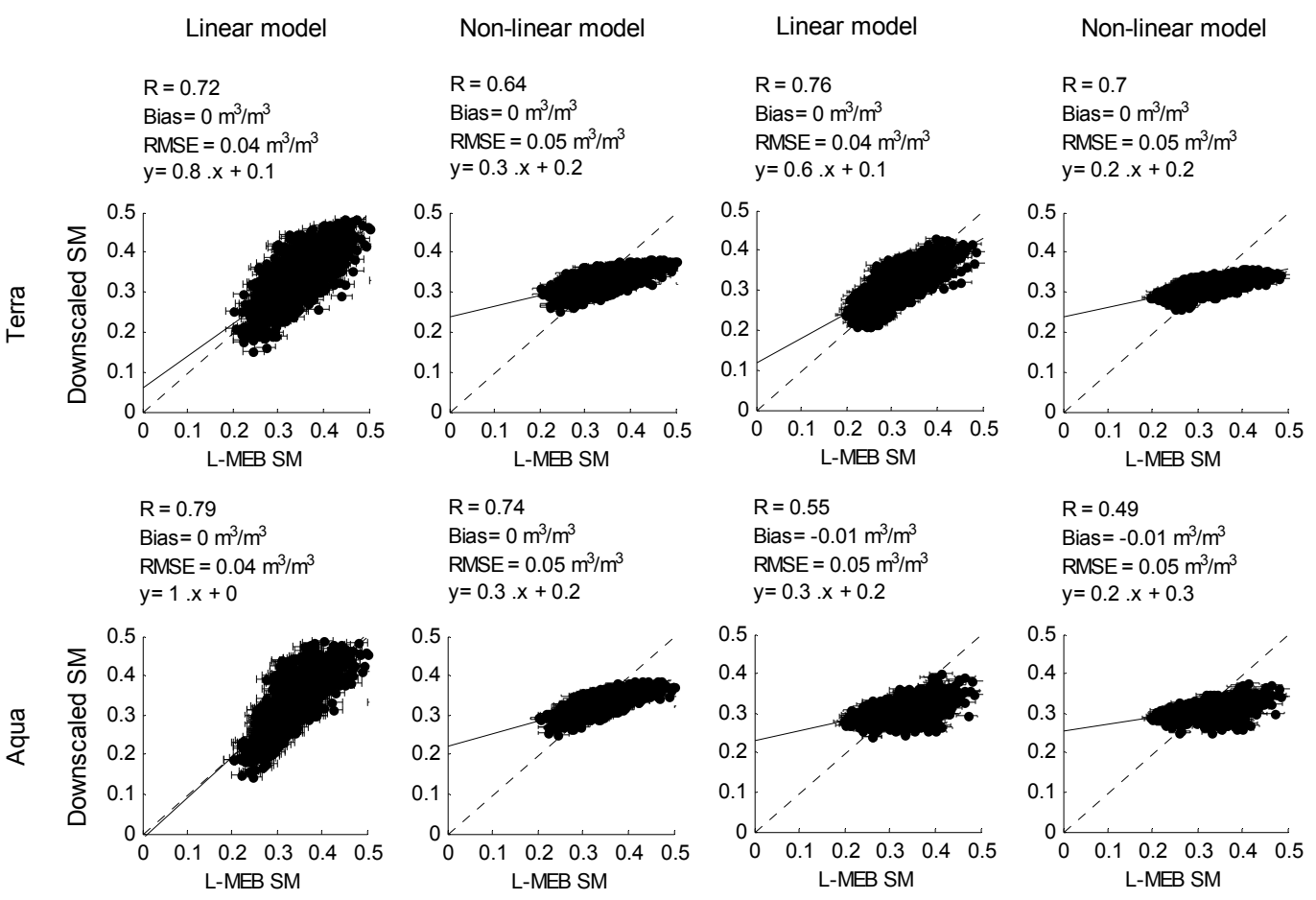

Figure 11: Day-time downscaled soil moisture compared to L-MEB derived soil

539 In summary, the results show that under very wet soil conditions the non-linear model

540 between SEE and SM provides better downscaled soil moisture from DISPATCH as used

541 by Merlin et al. (2012b). By improving the estimation of $T s_{\max }$, the linear model

542 between SEE and SM performs better. A sensitivity analysis was conducted to evaluate

543 the stability of the downscaling method by using the improved value of $T s_{\max }$.

\subsubsection{Sensitivity study}

545 Figure 12 presents dSM/dTsmax as a function of $T s_{\max }$ for the two selected SMOS

546 pixels located within the study site. The vertical bold line represents the

547 extrapolated $T s_{\max }$ value (Section 6.2.1) referred here as $T s_{\max -\bmod }$. Since

$548 T s_{\text {min-mod }}$ is lower than the origin of the $\mathrm{x}$ axis, it is not presented in Figure 12. Results

549 show that the downscaled soil moisture varies very slightly as a function of $T s_{\max }$, for 
550 both the linear and non-linear models. In fact, a variation of $1 \mathrm{~K}$ in $T s_{\max }$, from

$551 T s_{\max -\bmod }$ (red axis), generates a variation of the downscaled soil moisture lower than

$5520.03 \frac{\mathrm{m}^{3}}{\mathrm{~m}^{3}}$ and $0.01 \frac{\mathrm{m}^{3}}{\mathrm{~m}^{3}}$ for the linear and the non-linear models, respectively. By comparing

553 Figures 12 and 8 , it can be seen that the downscaled soil moisture results obtained using

554 the improved value of $T s_{\max }$ are less affected by $T s_{\max }$ than those obtained with

555 DISPATCH as used in Merlin et al. (2012b). The proposed method allows searching for

$556 T s_{\max }$ in a wider area, and appears as an interesting way to reduce the impact of its

557 uncertainty on the disaggregation process.

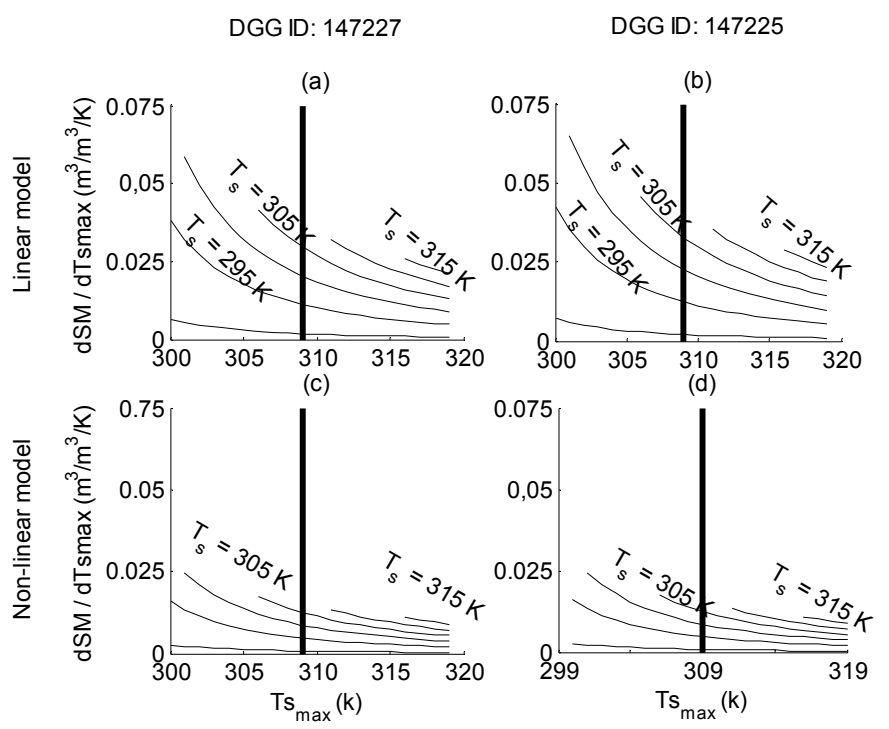

558

559

560

561

562

563 downscale the 40-km resolution SMOS soil moisture estimates over the agricultural site

564 of the CanEx-SM10 field campaign. The algorithm relies on the spatial link between the

565 optical/thermal derived Soil Evaporative Efficiency and near-surface soil moisture. Since

566 DISPATCH provided good results over semi-arid areas (Merlin et al., 2012b; Merlin et 
567 al., 2013), the objective of the present work was to evaluate its applicability for other soil

568 moisture conditions, in particular the very wet conditions encountered during CanEx-

569 SM10. This study also tested the suitability of using the linear or non-linear relationship

570 between the Soil Evaporative Efficiency derived from MODIS data and the near-surface

571 soil moisture for very wet soils. For validation purposes, the downscaled results were

572 compared to ground measured soil moisture and to the inverted soil moisture from the L-

573 MEB algorithm applied to L-band airborne passive microwave data.

574 The results show that under wet soil conditions, the non-linear model between SEE and

575 SM provides better downscaled soil moisture from the DISPATCH algorithm. This is in

576 contrast with the results found by Merlin et al. (2012b) for semi-arid areas, where the

577 linear model performed better. For wet soil conditions, the spatial variability of soil

578 moisture is low. The contrast between the minimum and maximum soil temperatures

579 required in the estimation of SEE becomes weaker. Indeed, because of the difficulty in

580 finding a dry surface inside the SMOS pixel, $\mathrm{Ts}_{\max }$ is underestimated. The linear model

581 tends to linearly stretch the narrow range of soil moisture values observed within the low

582 resolution pixel. As a result, pronounced slopes $(>1.4)$ were found between the

583 downscaled and ground-based or L-MEB derived soil moisture, in contrast to the slope

584 close to 1 found with the non-linear model. Indeed, for very wet soil conditions

585 characterized by low spatial variability, the non-linear model is able to artificially

586 compensate for systematic underestimation of $\mathrm{Ts}_{\max }$ and produce better results.

587 Furthermore, the downscaling results were found to be very sensitive to $T s_{\max }$

588 particularly with the linear model. Therefore, under wet soil conditions characterized by 
589 low spatial variability of soil moisture, the results obtained in this paper recommend the

590 use of the non-linear model in the DISPATCH downscaling algorithm.

591 For wet soil conditions, the estimation of the $T s_{\max }$ value is critical for the downscaling

592 process. Different approaches can be suggested to optimize the accuracy of $T s_{\max }$ to

593 make it more representative of a dry pixel (water content $\approx 0 \mathrm{~m}^{3} \cdot \mathrm{m}^{3}$ ) for the same

594 surface and atmospheric conditions. An extrapolation of $T s_{\max }$ from a previous dry

595 condition encountered in the same SMOS pixel or even considering an average value

596 representative of each period of the year could be an alternative. But, it is limited by the

597 difficulty in satisfying the uniformity of the atmospheric forcing conditions necessary for

598 the application of the DISPATCH downscaling method. As for the use of a land surface

599 model to estimate $T s_{\max }$, it requires a considerable number of accurate ground-based

600 datasets, which are not always available. However, under very wet soil conditions,

601 extrapolating $T s_{\max }$ from the neighboring dry surface is less cumbersome and could be

602 efficient. Over an area larger than the SMOS pixel, the spatial variability of soil moisture

603 should be greater, and drier soils may be encountered. This increases the possibility of

604 obtaining better estimates of $T s_{\max }$. Therefore, we proposed to extrapolate the

605 temperature end-members from high-resolution optical data within the entire Kenaston

606 site instead of the SMOS pixel. This resulted in a higher value of $T s_{\max }$, which should be

607 more representative of a dry soil condition. Consequently, the results obtained from the

608 linear model performed better at fine scale than those gained from the non-linear model,

609 both in terms of correlation and slope with the ground data and the L-MEB inverted soil

610 moisture. Moreover, the results of the downscaling process become quasi-invariant when

611 the estimated $T s_{\max }$ is equal to or greater than to the improved value. 
612 In examining the results, we found lower correlations and slopes when the SMOS/Aqua

613 combination is compared to L-MEB derived soil moisture for DOY 165. The difference

614 with the results from SMOS/Terra can be attributed to the substantial incidence angle of

615 the Aqua instrument $\left(\theta>60^{\circ}\right)$ compared to Terra $\left(\theta\right.$ between $20^{\circ}$ and $\left.40^{\circ}\right)$. The study

616 also showed that SMOS/Aqua and SMOS/Terra downscaled soil moisture maps are very

617 similar. This is important since the combination of MODIS Terra and MODIS Aqua

618 products (surface temperature and NDVI) could be used to minimize the data gaps due to

619 cloud cover. Good correlation $(\mathrm{R}>0.85)$ is also found between the downscaled soil

620 moisture from the linear and non-linear models.

621 It is important to note that extending the search area is a trade-off between capturing 622 enough variability in soil moisture and meeting the condition of relatively uniform 623 atmospheric conditions. Thus, future studies are needed to develop methods that define 624 the smallest, sufficient spatial extent to calibrate $T s_{\max }$ (and may be $T s_{\min }$ in case of a 625 dry soil), and the maximum spatial extent in which the atmospheric conditions could be 626 considered uniform.

627 Finally, this paper shows the importance of using the appropriate linear or non-linear 628 model between the soil evaporative efficiency and the near surface soil moisture when 629 using the DISPATCH algorithm to downscale coarse resolution SMOS soil moisture.

630 Cloud free conditions are a limitation of the daily applicability of the DISPATCH 631 downscaling algorithm, compared to passive/active microwave combination, which is 632 independent of the atmospheric conditions. Our future work will consider cloudy 633 situations. 
636 This study was funded by the Natural Sciences and Engineering Research Council of

637 Canada-Strategic program grant. The authors would like to thank the funding agencies of

638 CanEx-SM10 (Natural Sciences and Engineering Research Council of Canada,

639 Environment Canada, Canadian Space Agency, Agriculture and Agri-Food Canada,

640 National Aeronautics and Space Administration, United States Department of

641 Agriculture) and all the CanEx-SM10 participants. We also thank the CESBIO SMOS

642 team for their collaboration, the European Space Agency (ESA) for providing the SMOS

643 data, and the anonymous reviewers for their comments and suggestions to improve the

644 quality of the paper.

\section{References}

646 Carlson, T. N., Gillies, R. R., Perry, E. M. (1994). A method to make use of thermal infrared 647 temperature and NDVI measurements to infer soil water content and fractional vegetation 648 cover. Remote Sensing Reviews, 52, 45-59.

649 Das, N. N., Entekhabi, D., Njoku, E.G. (2011). An Algorithm for Merging SMAP 650 Radiometer and Radar Data for High-Resolution Soil-Moisture Retrieval, IEEE 651 Transactions on Geoscience and Remote Sensing, 49, 1504-1512.

652 Djamai, N., Magagi, R., Goita, K., Hosseini, M., Cosh, M.H, Berg, A., Toth, B. (2015). 653 Evaluation of SMOS soil moisture products over the CanEx-SM10 area. Journal of 654 Hydrology, 520, 254-267.

655 Chauhan, N. S., Miller, S., Ardanuy, P. (2003). Spaceborne soil moisture estimation at high 656 resolution: a microwave-optical/IR synergistic approach. International Journal of Remote 657 Sensing, 24, 4599-4622.

658 Cosby, B. J., Hornberger, G.M., Clapp, R. B., \& Ginn, T. R. (1984). A statistical exploration 659 of the relationships of soil moisture characteristics to the physical properties of soils. 660 Water Resources Research, 20, 682-690.

661 Elbialy, S., Mahmoud, A., Pradhan, B., Buchroithner, M. (2014) Application of spaceborne 662 synthetic aperture radar data for extraction of soil moisture and its use in hydrological 663 modelling at Gottleuba Catchment, Saxony, Germany. Journal of Flood Risk 664 Management, 7, 159-175.

665 Entekhabi, D., Njoku, E. G., O'Neill, P. E., Kellogg, K. H., Crow, W. T., Edelstein, W. N., 666 et al. (2010). The Soil Moisture Active Passive (SMAP) mission. Proceedings of the 667 IEEE, 98, 704-716. 
668 Flato, G.M., Boer, G.J, Lee, W.G., McFarlane, N., Ramsden, D., Reader, M.C., Weaver, 669 A.J. (2000). The Canadian Centre for Climate Modelling and Analysis global coupled 670 model and its climate. Climate Dynamics, 16 (6), 451-467.

671 Gherboudj, I., Magagi, R., Goïta, K., Berg, A., Toth, B., Walker, A. (2012). Validation of 672 SMOS data over agricultural and boreal forest areas in Canada. IEEE Transactions on 673 Geoscience and Remote Sensing, 50, 1623-1635.

674 Idso,T. Schmugge, R. Jackson, Reginto, R. (1975). The utility of surface temperature 675 measurements for remote sensing of soil water studies. Journal of Geophysical Research, $67680,3044-3049$.

677 Kerr, Y. H. (2007). Soil moisture from space: Where are we? Hydrogeology Journal, 15, 678 117-120.

679 Kerr, Y. H., P. Waldteufel, P. Richaume,P., Wigneron, J.P., Ferrazzoli, P., Mahmoodi, A., 680 Al Bitar, A., Cabot, F., Gruhier, C., Juglea, S.E., Leroux, D., Mialon, A., and Delwart, S. 681 (2012). The SMOS soil moisture retrieval algorithm. IEEE Transactions on Geoscience 682 and Remote Sensing, 50, 1384-1403.

683 Kerr, Y.H., Waldteufel, P., Wigneronand, J.P., Delwart, S., Cabot, F., Boutin, J., 684 Escorihuela, M. J., Font, J., Reul, N., Gruhier, C., Juglea, S.E., Drinkwater, M.R., Hahne, 685 A., Martin-Neira, M., and Mecklenburg, S. (2010.) The SMOS Mission: New Tool for 686 Monitoring Key Elements of the Global Water Cycle. IEEE Transactions on Geoscience 687 and Remote Sensing, 98, $666-687$.

688 Kim, J., and Hogue, T.S. (2012). Improving Spatial Soil Moisture Representation through 689 Integration of AMSR-E and MODIS Products. IEEE Transactions on Geoscience and 690 Remote Sensing, 50, 446-460.

691 Laprise, R. (2008). Regional climate modelling. Journal of Computational Physics, 227(7), 692 3641-3666.

693 Loew, A., Stacke, T., Dorigo, W., de Jeu, R., Hagemann, S. (2013) Potential and limitations 694 of multidecadal satellite soil moisture observations for climate model evaluation studies. 695 Hydrology and Earth System Sciences Discussions, 10, 3541-3594.

696 Magagi R., Berg A., Goïta K., Belair S., Jackson T., Toth B., Walker A., McNairn H., 697 Peggy, O., Moghaddam M., Gherboudj I., Colliander A., Cosh M., Burgin M., Fisher J.

698 B., Kim S.B., Mladenova I., Djamai N., Rousseau L.P., Belanger J., Shang J., and 699 Merzouki A. (2013). CanEX-SM 10 (Canadian Experiment for Soil Moisture in 2010):

700 Overview and Preliminary results. IEEE Transactions on Geoscience and Remote 701 Sensing, 51, 347-363.

702 Manabe, S. (1969). Climate and the ocean circulation. I. The atmospheric circulation and the 703 hydrology of the Earth's surface. Monthly Weather Review, 97, 739-774.

704 Merlin, O., Escorihuela, M.J., Mayoral, M.A., Hagolle, O., Al Bitar, A., Kerr, Y. (2013). 705 Self-calibrated evaporation-based disaggregation of SMOS soil moisture: an evaluation 706 study at $3 \mathrm{~km}$ and $100 \mathrm{~m}$ resolution in Catalunya, Spain. Remote Sensing of 707 Environment, 13, 25-38. 
708 Merlin, O., Jacob, F., Wigneron, J.P., Walker, J., Chahbouni, G. (2012a). Multidimensional 709 Disaggregation of Land Surface Temperature Using High-Resolution Red, Near-Infrared, 710 Shortwave-Infrared, and Microwave-L Bands. IEEE Transactions on Geoscience and 711 Remote Sensing, 50, $1864-1880$.

712 Merlin, O., Rüdiger, C., Al Bitar, A., Richaume, P.,Walker, J.P., Kerr, Y.H. (2012b). 713 Disaggregation of SMOS soil moisture in Southeastern Australia. IEEE Transactions on 714 Geoscience and Remote Sensing, 50, 1557-1571.

715 Merlin, O.,Walker, J. P., Chehbouni, A., Kerr, Y. (2008). Towards deterministic 716 downscaling of SMOS soil moisture using MODIS derived soil evaporative efficiency. 717 Remote Sensing of Environment, 112, 3935-3946.

718 Moran, M. S., Clarke, T. R., Inoue, Y., Vidal, A. (1994). Estimating crop water deficit using 719 the relation between surface-air temperature and spectral vegetation index. Remote 720 Sensing of Environment, 49, 246-263.

721 Narasimhan, B., Srinivasan, R. (2005). Development and evaluation of Soil Moisture Deficit 722 Index (SMDI) and Evapotranspiration Deficit Index (ETDI) for agricultural drought 723 monitoring. Agricultural and Forest Meteorology, 133, 69-88.

724 Nishida, K., Nemani, R. R., Glassy, J. M., Running, S. W. (2003). Development of an 725 evapotranspiration index from Aqua/MODIS for monitoring surface moisture status. 726 IEEE Transactions on Geoscience and Remote Sensing, 41, 493-501.

727 Njoku, E.G., Jackson, T.J., Lakshmi, V., Chan, T.K. (2003) Soil moisture retrieval from 728 AMSR-E. IEEE Transactions on Geoscience and Remote Sensing, 41, 215 - 229.

729 Njoku, E.G, Entekhabi, D., (1996). Passive microwave remote sensing of soil moisture. 730 Journal of Hydrology, 184, 101-129.

731 Piles, M., Camps, A., Vall-llossera, M., Corbella, I., Panciera, R., Rudiger, C., Kerr, Y.H., 732 Walker, J. (2011). Downscaling SMOS-Derived Soil Moisture Using MODIS 733 Visible/Infrared Data. IEEE Transactions on Geosciences and Remote Sensing, 49, 31567343166.

735 Rahimzadeh-Bajgiran, P., Berg, A., Champagne, C., Omasa, K. (2013). Estimation of soil 736 moisture using optical/thermal infrared remote sensing in the Canadian Prairies. ISPRS 737 Journal of Photogrammetry and Remote Sensing, 83, 94-103.

738 Salathé J.E.P., Leung, L.R., Qian, Y., Zhang, Y., (2010). Regional climate model 739 projections for the State of Washington. Climatic Change, 102, 51-75.

740 Sánchez-Ruiz, S., Piles, M., Sánchez, N., Martínez-Fernández, J., Vall-llossera, M., Camps, 741 A. (2014). Combining SMOS with visible and near/shortwave/thermal infrared satellite 742 data for high resolution soil moisture estimates. Journal of Hydrology, 516, 273-283.

743 Scinocca, J., McFarlane, N., Lazare, M., Li, J., and Plummer, D. (2008). The CCCma third 744 generation AGCM and its extension into the middle atmosphere, Atmospheric Chemistry 745 and Physics Discussions, 8, 7883-7930.

746 Wagner, W., Hahn, S., Kidd, R., Melzer, T., Bartalis, Z., Hasenauer, S., Figa-Saldanấ, J., et 747 al. (2013). The ASCAT soil moisture product: A review of its specifications, validation

748 results, and emerging applications. Meteorologische Zeitschrift, 22, 5-33. 
749 Wang, X., Xie , H., Guan, H., Zhou, X. (2007). Different responses of MODIS derived 750 NDVI to root-zone soil moisture in semi-arid and humid regions. Journal of Hydrology 751 and Earth System Sciences, 340, 12-14.

752 Weidong, L., Baret F., Xingfa, G., Zhang, B., Qingxi, T. and Lanfen, Z. (2003). Evaluation 753 of methods for soil surface moisture estimation from reflectance data. International 754 Journal of Remote Sensing, 24, 2069-2083.

755 Wigneron, J.P., Kerr, Y. H., Waldteufel, P., Saleh, K., Escorihuela, M.J., Richaume, P., 756 Ferrazzoli, P., De Rosnay, P., Gurney, R., Calvet, J.C., Grant, J.P., Guglielmetti, M., 757 Hornbuckle, B., Mätzler, C., Pellarin, T., Schwank, M. (2007). L-band Microwave 758 Emission of the Biosphere (L-MEB) Model: Description and calibration against 759 experimental data sets over crop fields. Remote Sensing of Environment, 13, 639-655. 